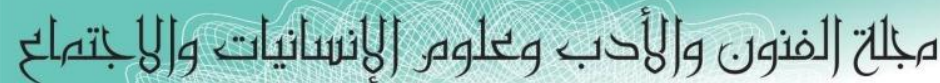
Journal of Arts, Literature, Humanities and Social Sciences

ISSN online: 2414 - 3383

ISSN print: 2616 - 3810

العدد (43)

\title{
درجة توافر متطلبات تطبيق الإدارة الإلكترونية في مدارس التعليم الأساسي وما بعد الأساسي في محافظتي لإني مسقط وجنوب الباطنة
}

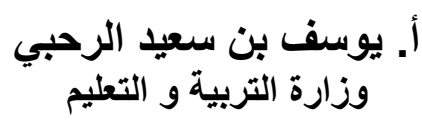

\author{
د. عبدالعزيز عطالله المعايطة

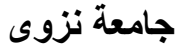

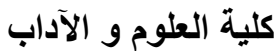 \\ قسم التربية و الاراسات الإنسانية
}

الملخص

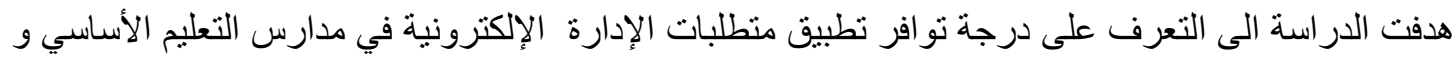

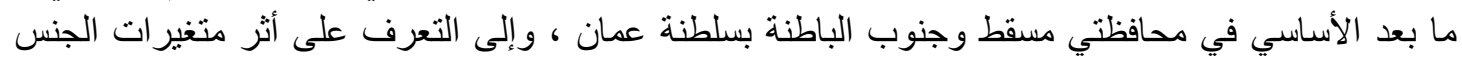

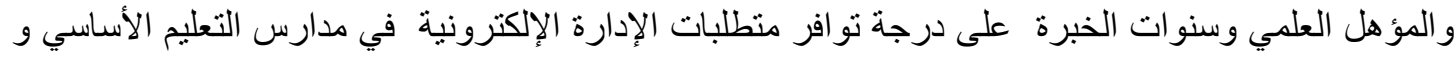

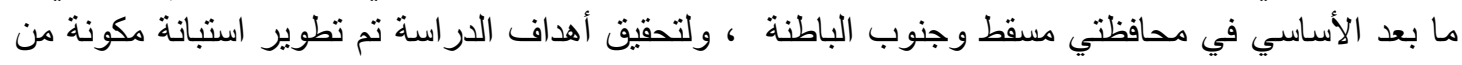

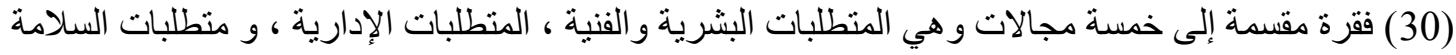

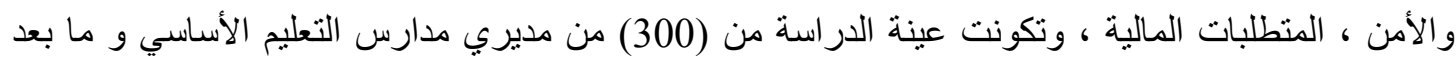

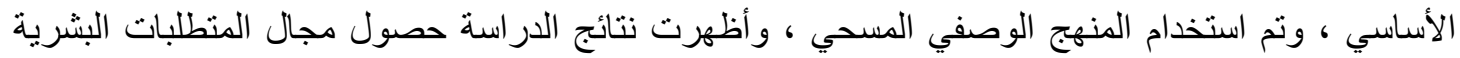
و الفنية و المتطلبات المادية و المتطلبات المالية والدرجة الكلية على درجة كبيرة ، و المنطلبات الإدارية ومتطلبات

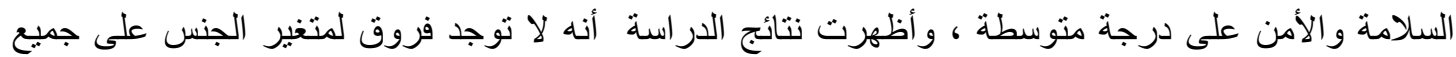

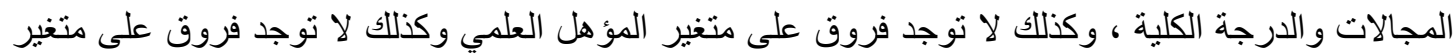

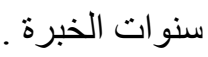
وأوصت الدر اسة بالقيام بتأهيل الكو ادر الإدارية حول التخطيط الإلكتروني كمنطلب أساسي للإدارة الإلكترونية. 


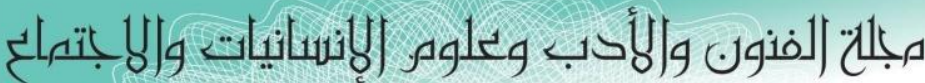

Journal of Arts, Literature, Humanities and Social Sciences

ISSN online: 2414 - 3383

ISSN print: 2616 - 3810

أيلول - سبتهبر 2019

العدد (43)

\title{
Degree of the Availability of the Requirements of Implementing the Electronic Administration in the School of Basic and Post Basic Education of Muscat and Batina of South Governorate
}

\author{
Dr. Abdul Aziz Atallah Al Maayta \\ University of Nizwa \\ Faculty of Arts and Sciences \\ Department of Education and Cultural Studies
}

\author{
Ms. Yousef saied AL-Rhbi \\ Ministry of Education
}

\begin{abstract}
This aims to explore the Degree of the requirements of applying the electronic administration in the school of Basic and post Basic education of Muscat and AlBatin al_south governorate and to identify the impact of the variables of gender ,qualifications , and years of service in the degree of the availability of the requirements of application on of the electronic administration in the school of basic and post Basic education of Muscat and AlBatin al-south governorate to achieve the objectives of the study the researchers developed questionnaire which consisted of 30 items divided in to five areas : technical skills requirements ,administrative, physical requirements, safety and security requirements, and financial requirements, the sample of the study of 300 basic and post basic education principals , the study used the descriptive survey method. The results of the study showed that the scores of technical skills requirements, material requirements,
\end{abstract}

Financial requirements and the total score were high, whereas the scores of administrative requirements and of safety and security requirements were average. There were no significant differences due to the variable of gender and the total score. There were also no significant differences due to the variable of the years of experience. There were no significant differences due to the variable of qualifications and the total score. The study recommended the need to rehabilitate the administrative staff of electronic planning as a prerequisite for electronic administrative. 


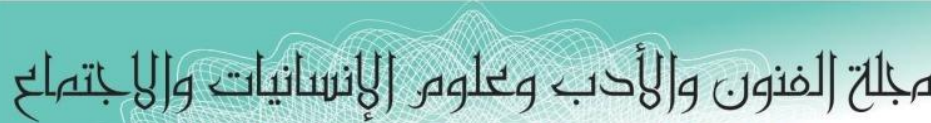 Journal of Arts, Literature, Humanities and Social Sciences}

ISSN online: 2414 - 3383

ISSN print: 2616 - 3810

\section{أيلول - سبتمبر 2019}

\section{العدد (43)}

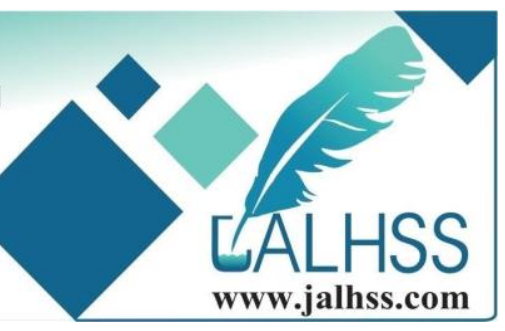

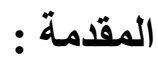

يتميز القرن الحادي و العشرين بالتقام التكنولوجي ، و المعلوماتي و التقني ، و إنتشار الثقافة الإلكترونية بشكل التشكل

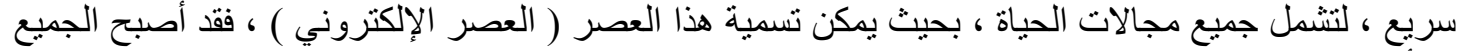

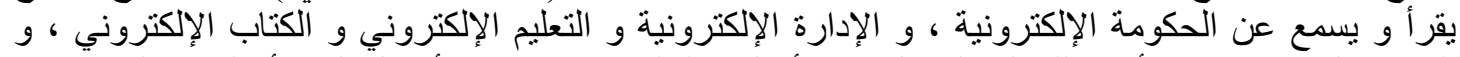

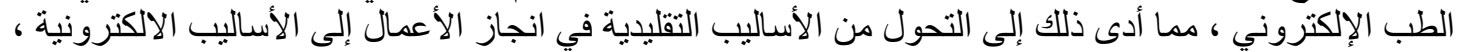

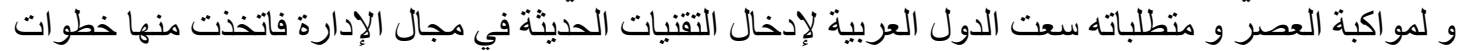

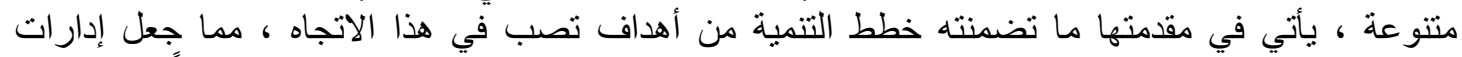

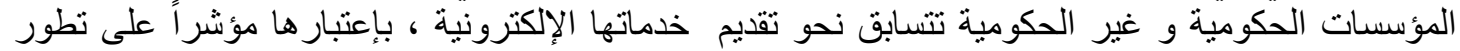

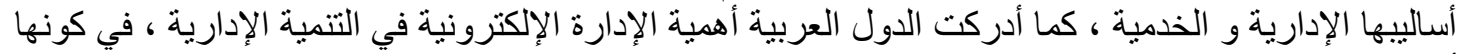

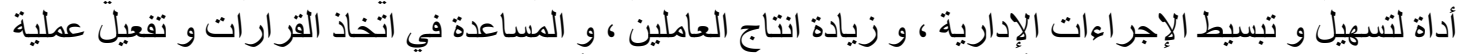

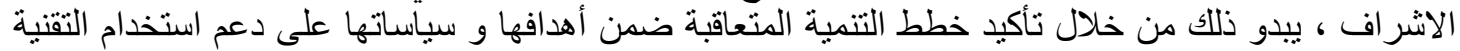

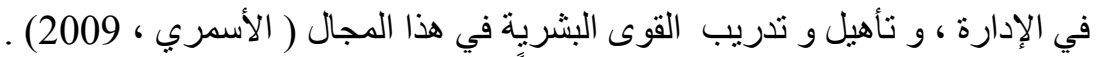

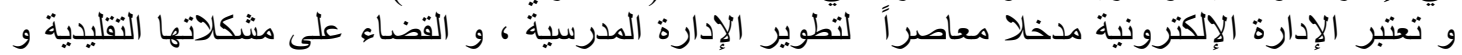

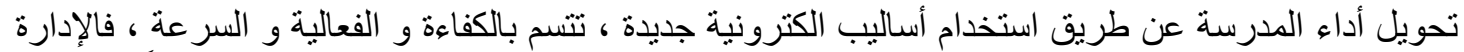

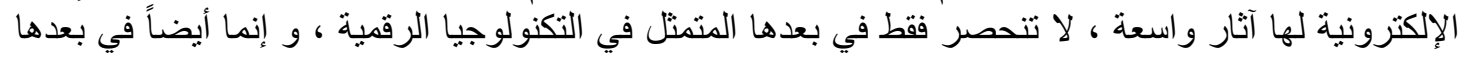

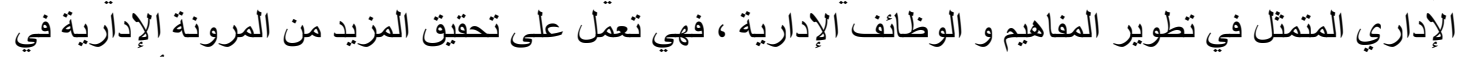

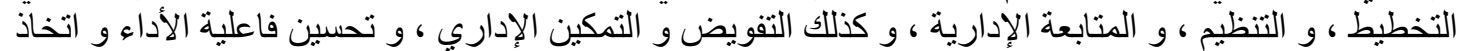

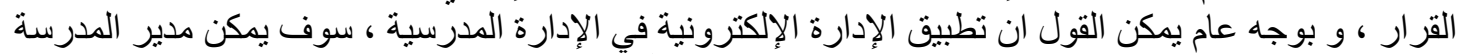

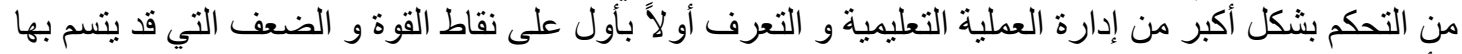

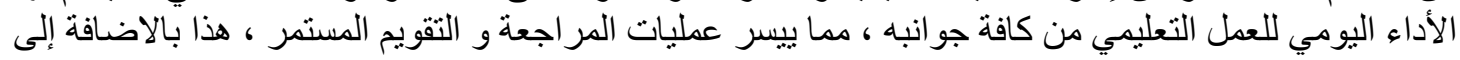

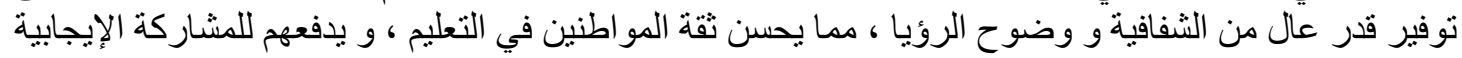

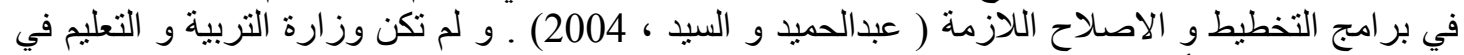

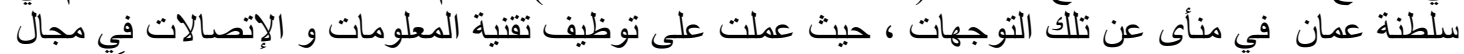

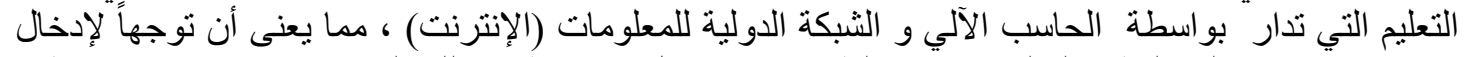

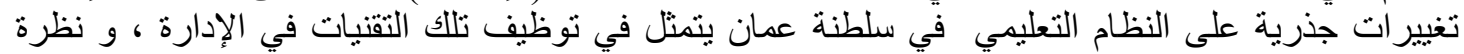

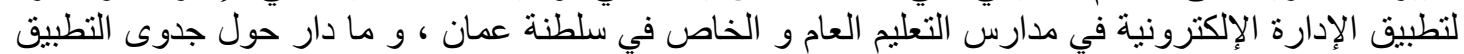

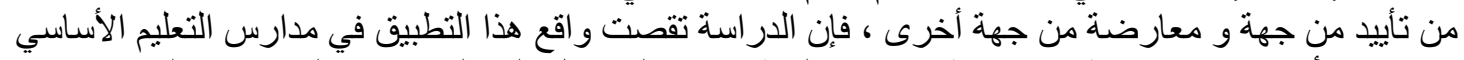

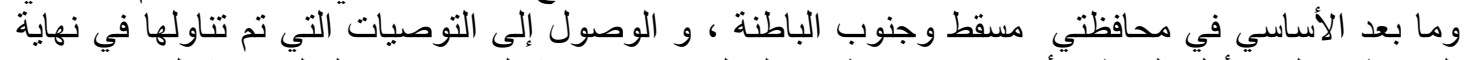

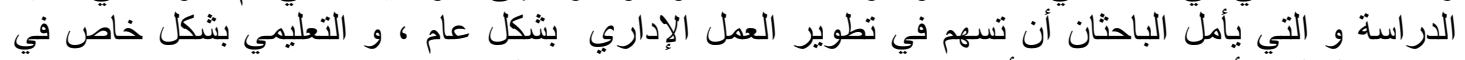

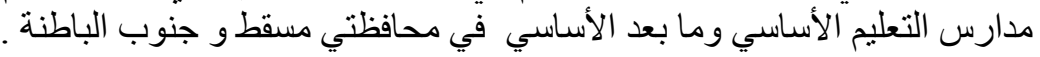

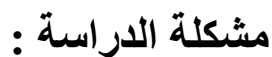

مع بدايات القرن الحادي و العشرين ، و و ظهور الثورة المعلوماتية ، و حدوث الطفئة الطفرة التكنولوجية الهائلة في

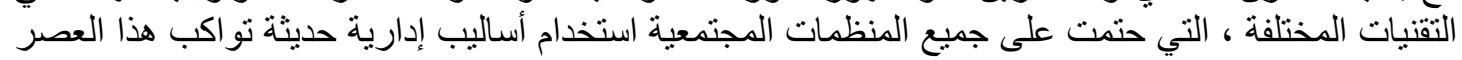

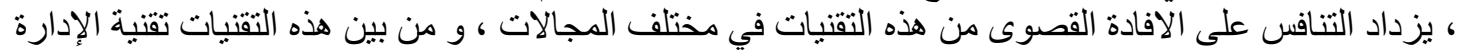

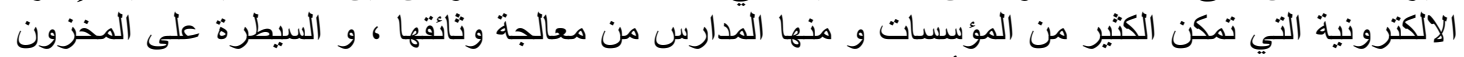

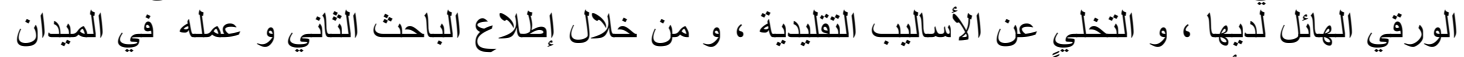

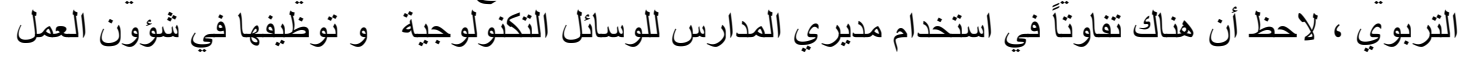

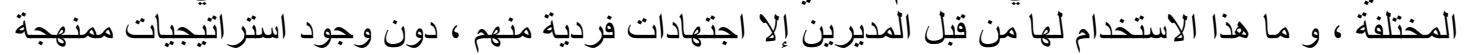

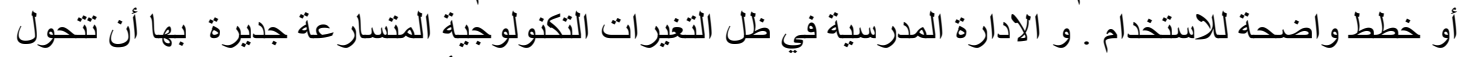

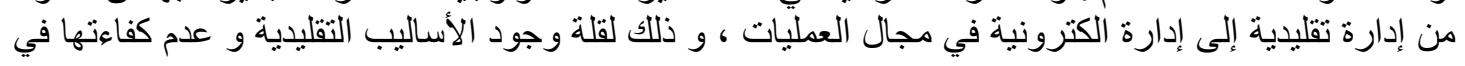




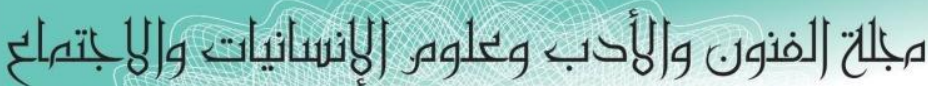

Journal of Arts, Literature, Humanities and Social Sciences

ISSN online: 2414 - 3383

ISSN print: 2616 - 3810

\section{العدد (43) ايلول -سبتمبر 2019}

العمل خاصة في ظل عصر الكتروني سريع التغير لذا يرى الباحثان أن التحول نحو تطبيق الادارة الالكترونية

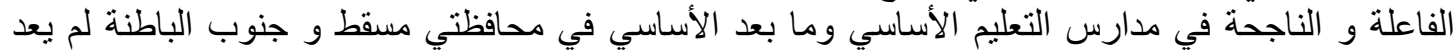

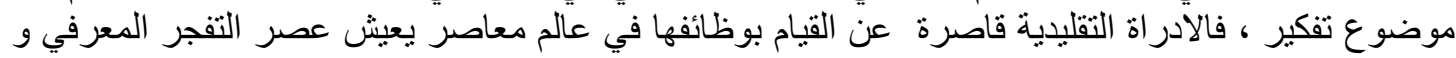

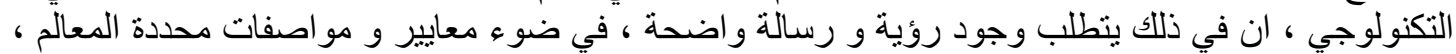

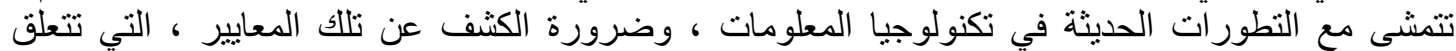

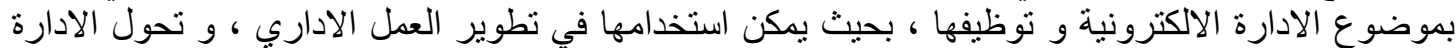

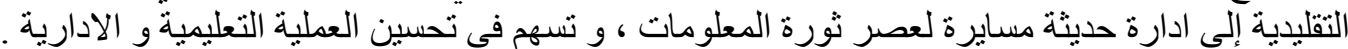

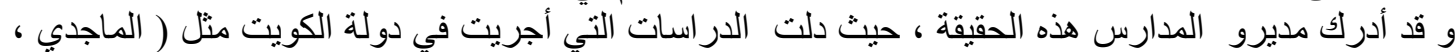

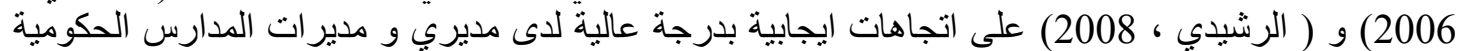

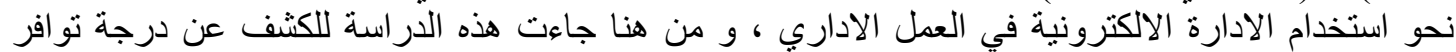

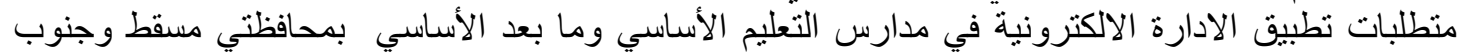

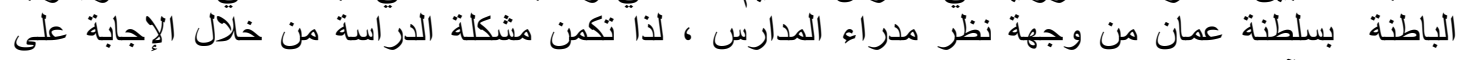

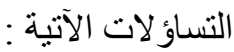

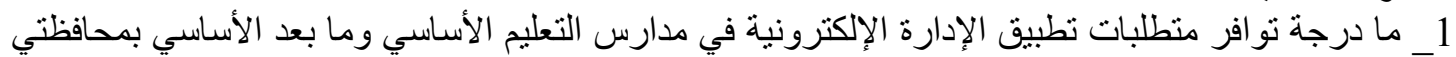

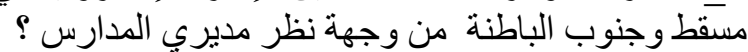
2- هل توجد فروق ذات دلالة احصائية عند مستوى $1 \leq 0.050$ ) بين متوسط تقدير عينة الدر اسة لدرجة تو افر

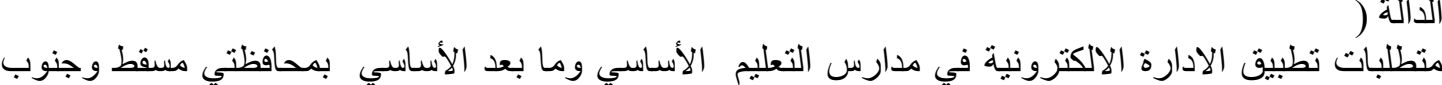
الباطنة تعزى لمتغيرات ( الجنس ، الخبرة ، المؤهل العلمي )

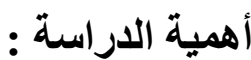 تكمن أهمية الدر اسة الحسة : الحية فيما يلي :

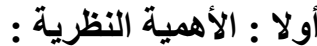

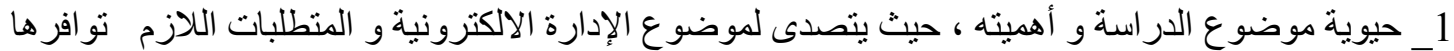

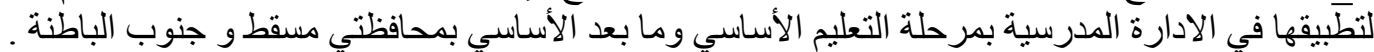

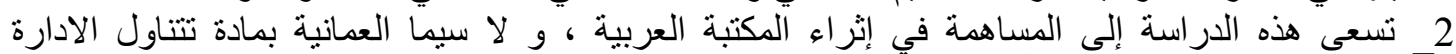

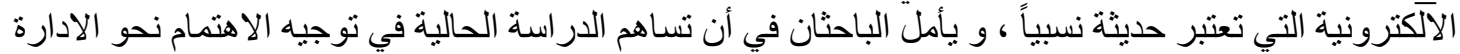

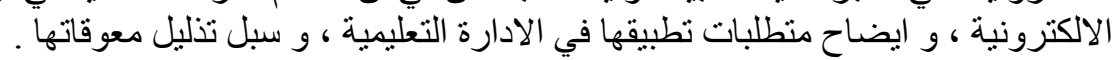

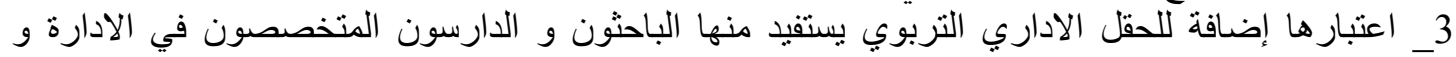

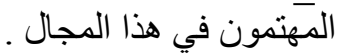

ثانيا : الأهمية التطبيقية :

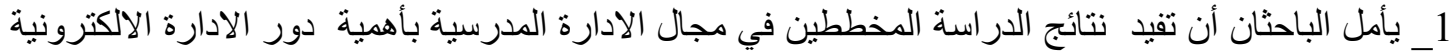

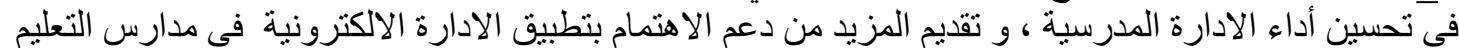

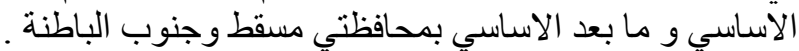

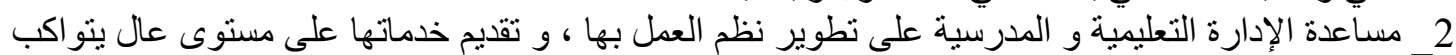

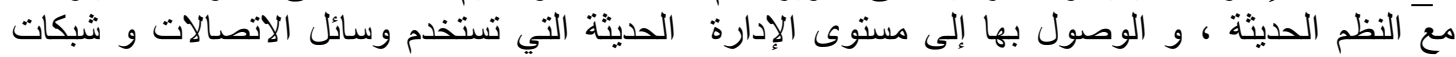

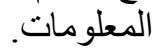




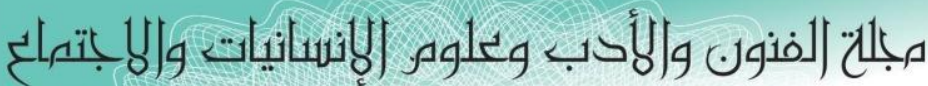

Journal of Arts, Literature, Humanities and Social Sciences

ISSN online: 2414 - 3383

ISSN print: 2616 - 3810

\section{أيلول - سبتهبر 2019}

العدد (43)

3_ سوف تزود الدراسة الحالية المسؤولين في الادارات المدرسية لمرحلة التعليم الاساسي و ما بعد الاساسي

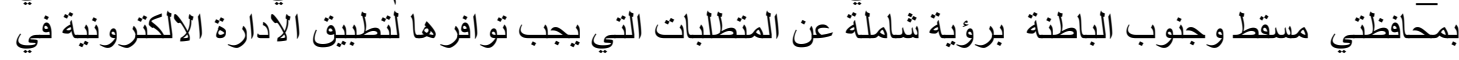

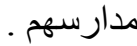

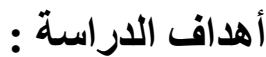

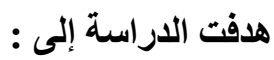

1 _تعرف درجة توافر متطلبات تطبيق الادارة الالكترونية في مدارس التعليم الأساسي وما بعد الأساسي

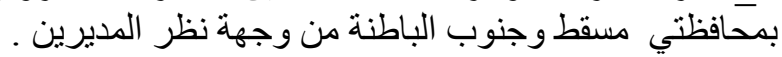

2_ الكثف عن دلالة الفروق في استجابات أفراد العينة لارجة متطلبات تطبيق الادارة الالكترونية في مدارس

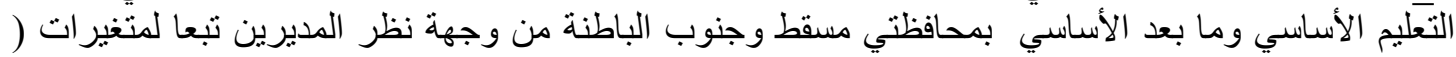

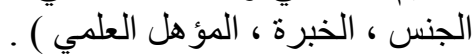

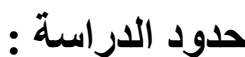

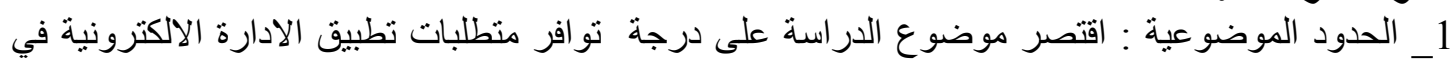

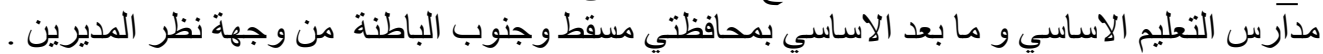
2_ الحدود الدكانيه : اقتصرت الدراسة على مدارس التعليم الأساسي و ما بعد الأساسي بمحافظتي مسقط

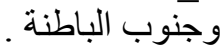
3_ الحدود البشرية : اقتصرت الدراسة على مديري و مديرات مدارس التعليم الأساسي و ما بعد الأساسي في

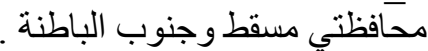

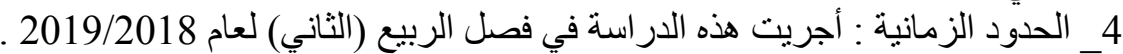
5- الحدود الدنهجية : تحددت نتائج هذه الدرأسة بصدقها ، و ثباتها ، و عينتها ، و أداتها ، و اجر اءعات تطبيقها .

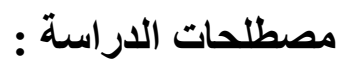
الإدارة الالكترونية : و تعني تحويل كافة العمليات الإدارية ذات الطبيعة الورقية إلى عمليات ذات طبيعة

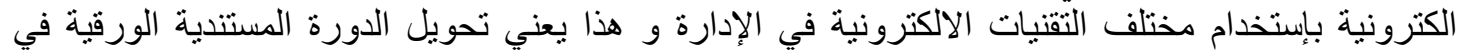

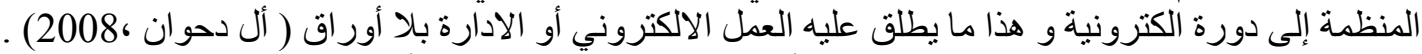

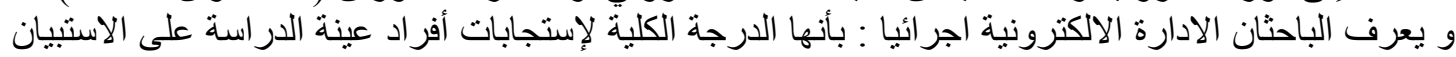

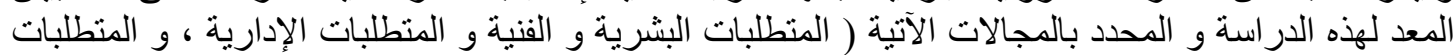
المادية و منطلبات الأمن و السلامة و المتطلبات المالية ) .

\section{متطبات تطبيق الادارة الاكترونية :}

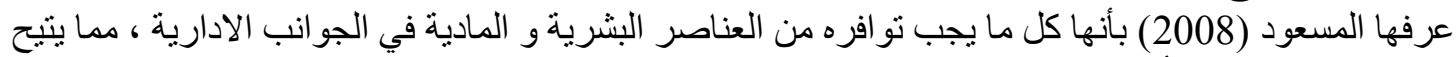

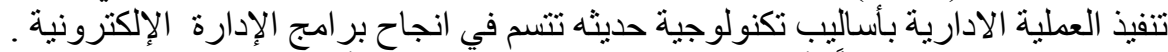

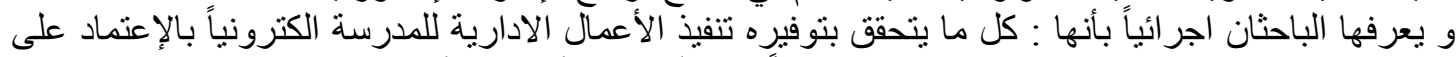

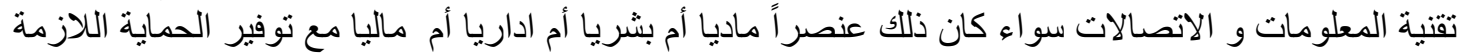

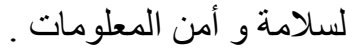

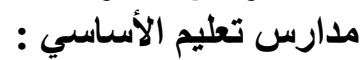
تعرف وزارة التربية و التعليم في سلطنة عمان التعليم الاساسي بأنه " تعليم موحد توفره الدولة لجميع الطيح أطفال

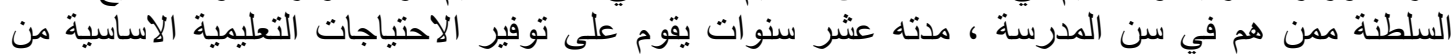




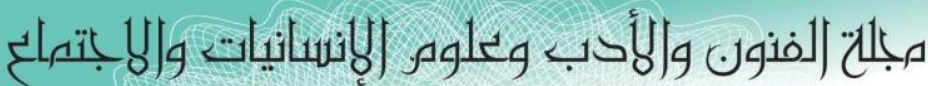

Journal of Arts, Literature, Humanities and Social Sciences

ISSN online: 2414 - 3383

ISSN print: 2616 - 3810

أيلول - سبتمبر 2019

العدد (43)

LALHSS

WWW.jalhss.com

المعلومات و المعارف و المهار ات ، و تتمية الاتجاهات و القيم التي تمكن المتعلمين من الاستمر ار في التعليم أو ألهات

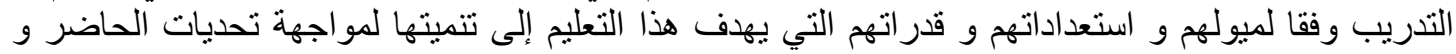
ظروفه ، و تطلعات المستقبل في إطار التنمية المجتمعية الثناملة (الرجيبي ، 2006:17)

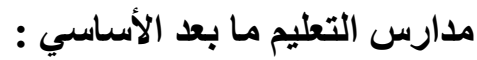

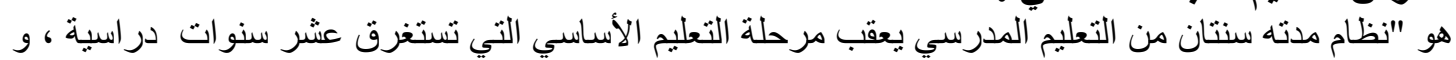

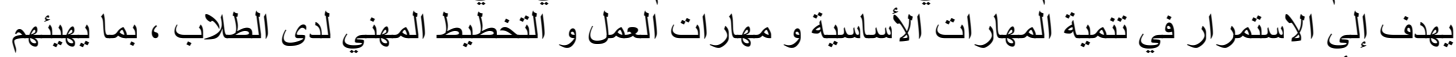

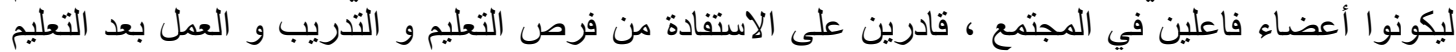
الدرسي " (وزارة التربية و التعليم ، قرار وزاري ، فارين ، 2007/160)

\section{الار اسات السابقة: الابة:

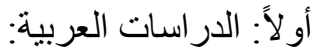

1-أجرى الربيعي (2019). دراسة هدفت للتعرف على درجة نطبيق الإدارة الإلكترونية في مدارس المملكة

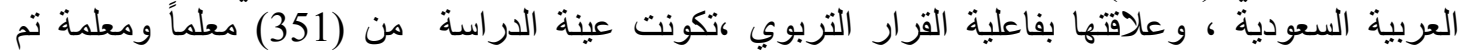

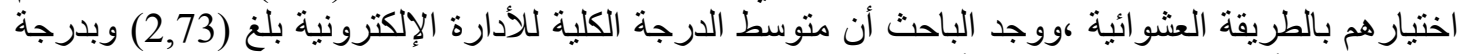

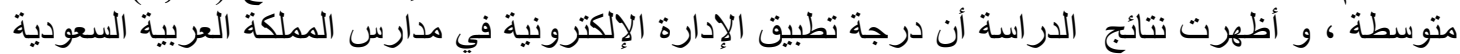

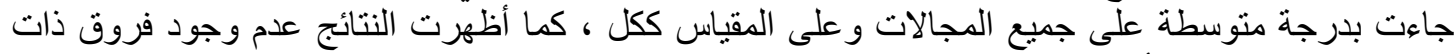

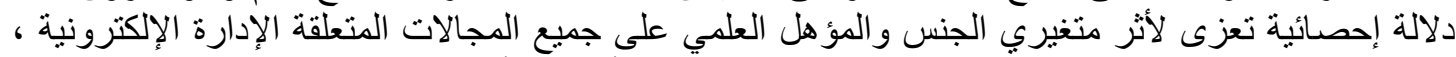

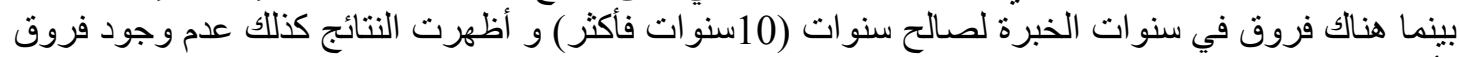

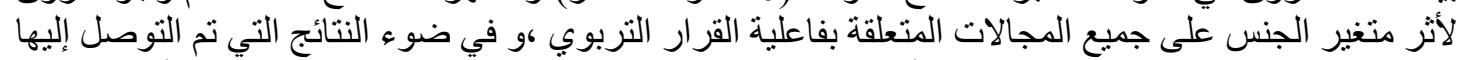

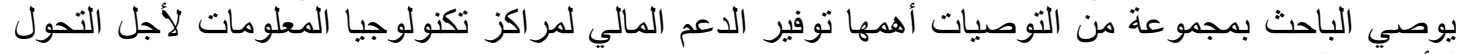

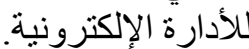
2- وقام الخو الدة (2015) بدراسة هدفت إلى الكثف عن والكانف واقع تطبيق الإدارة إلكترونية في المدارس الثانوية

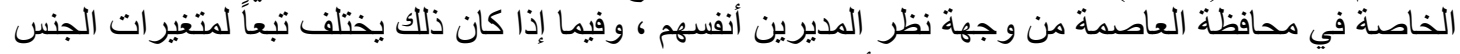

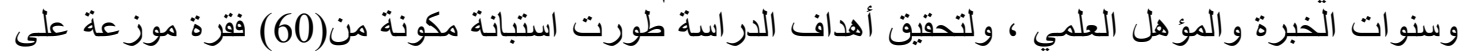

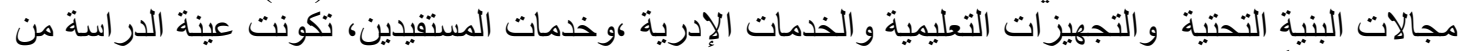

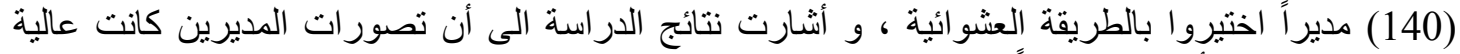

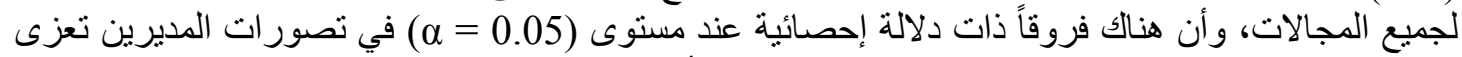

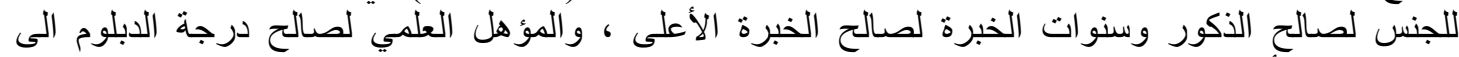
بكالوريوس فأعلى النى

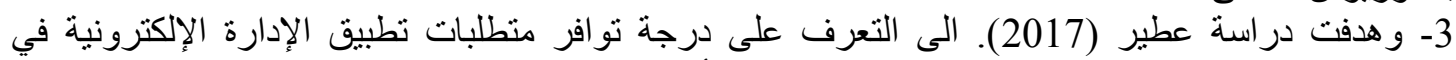

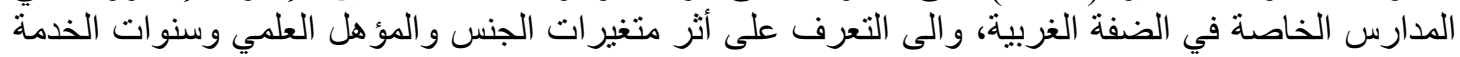

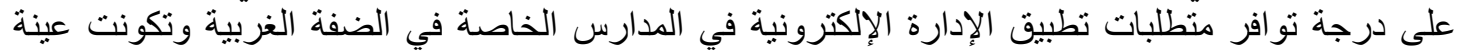

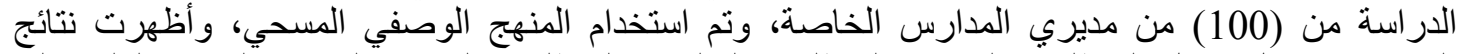

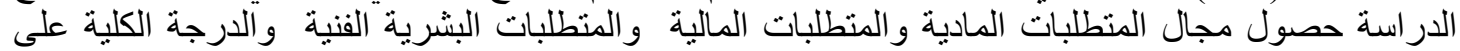

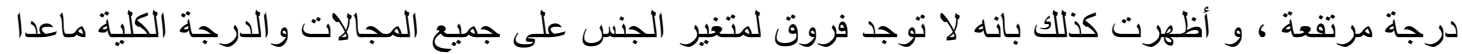

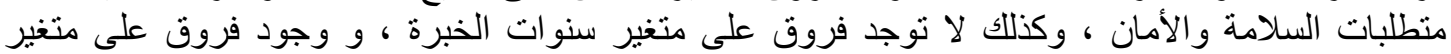

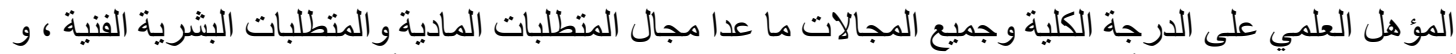

أوصت الدر استة بالقيام بتأهيل الكو ادر الإدارية حول التخطيط الإلكتروني كمنطلب أساسي للإدارة الالكترونية . 


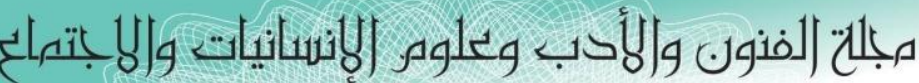

Journal of Arts, Literature, Humanities and Social Sciences

ISSN online: 2414 - 3383

ISSN print: 2616 - 3810

\section{العدد (43) أيلول - سبتمبر 2019}

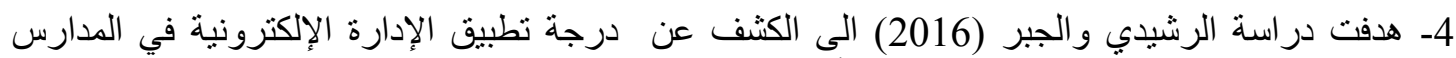

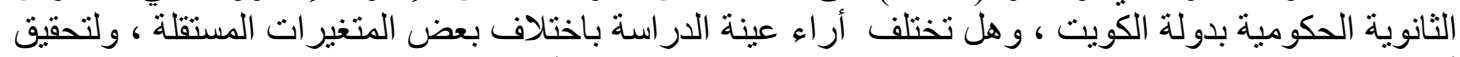

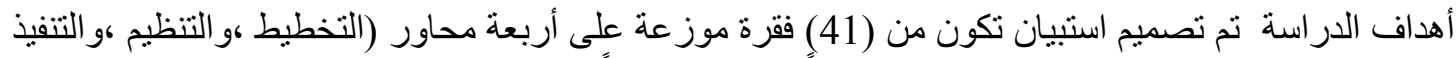

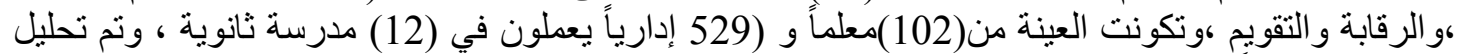

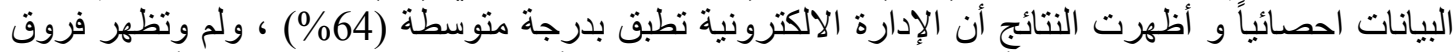

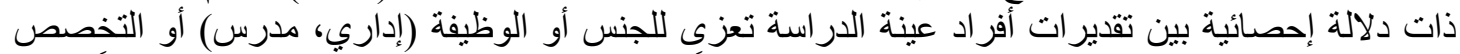

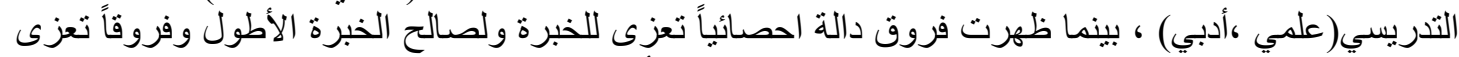

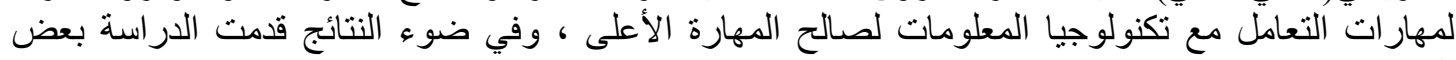

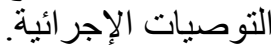

5- وقام النعمان (2016) بدراسة هدفت الى التعرف على درجة دورة توافر متطلبات الإدارة الإلكترونية بأمانة

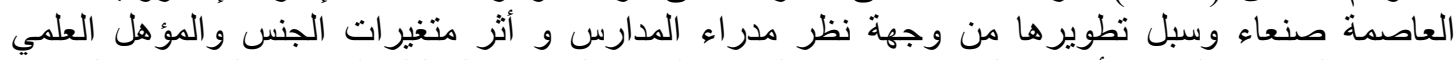

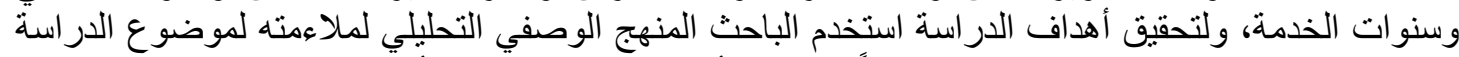

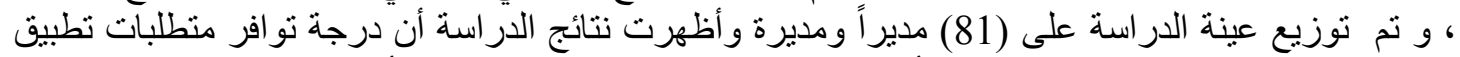

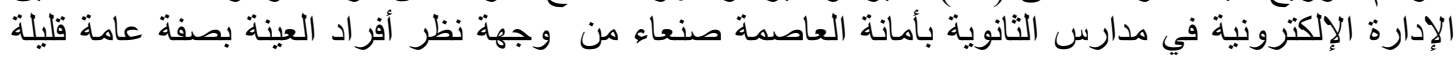

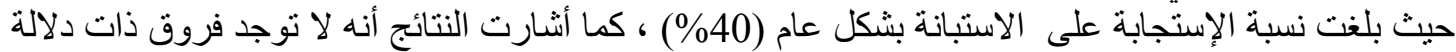

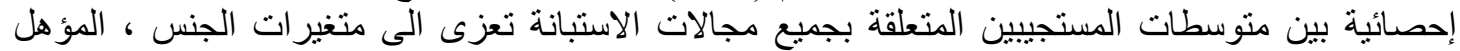

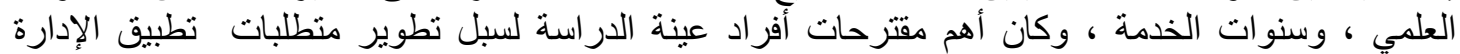

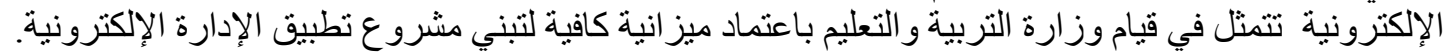

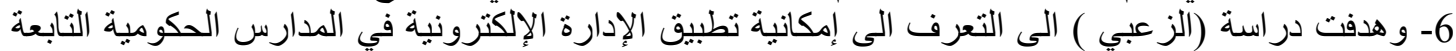

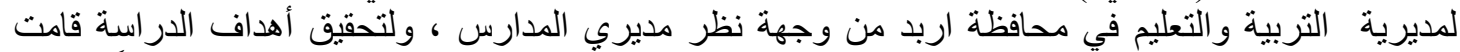

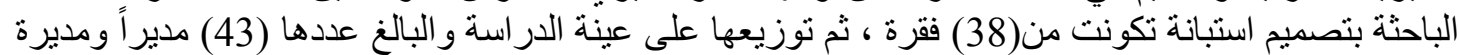

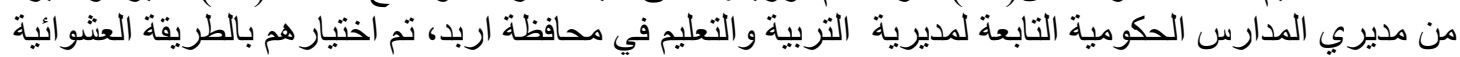

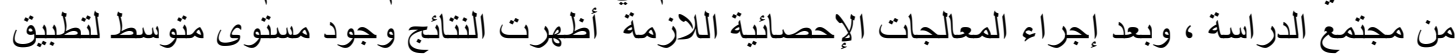

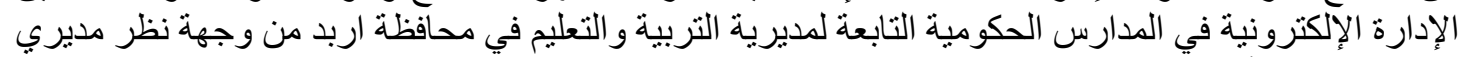

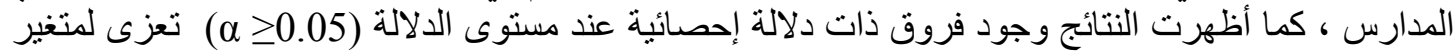

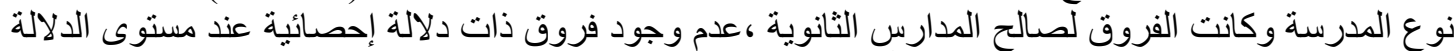

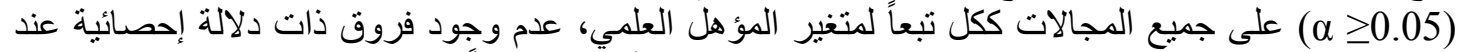

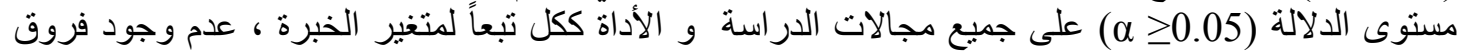

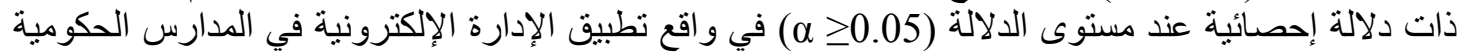
في اربد نعزى لمتغير نوع المدرسة.

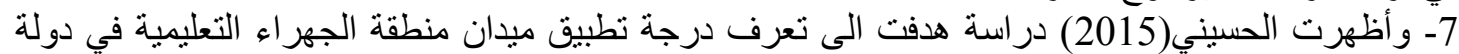

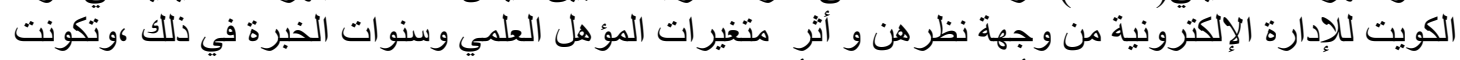

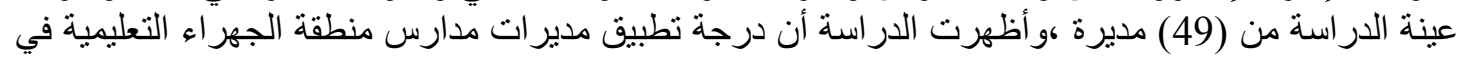

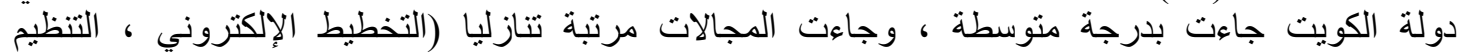

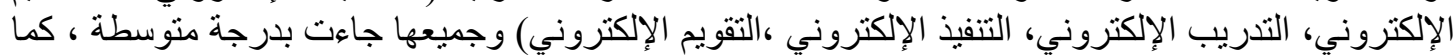

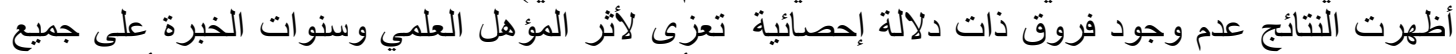

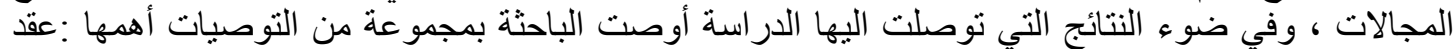
دورات تدريبية لمديرات المدارس على تطبيقات الإدارة الإلكترونية في المدارس. 


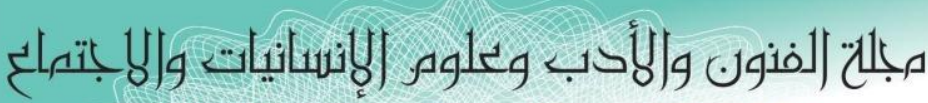
Journal of Arts, Literature, Humanities and Social Sciences

ISSN online: 2414 - 3383

ISSN print: 2616 - 3810

العدد (43) ايلول - سبتمبر 2019

LALHSS

WwW.jalhss.com

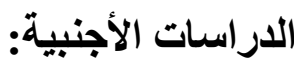

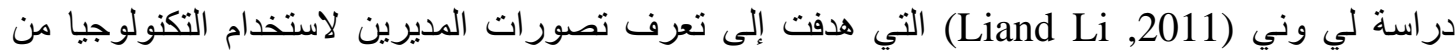

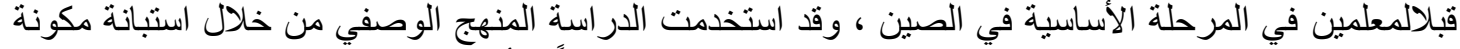

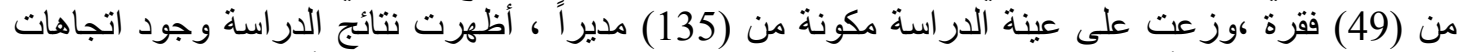

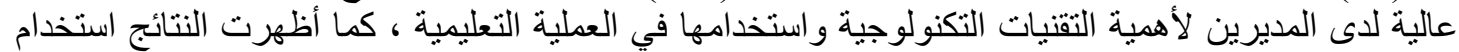

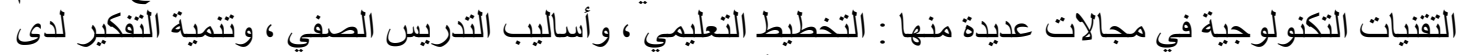

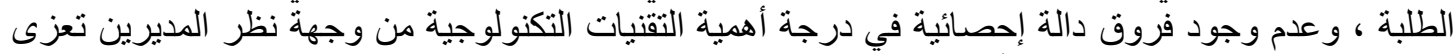

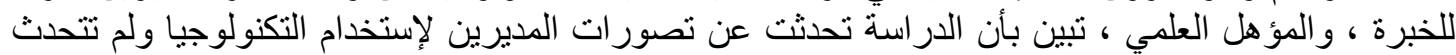

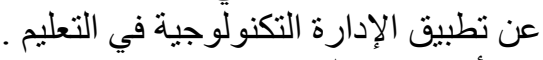

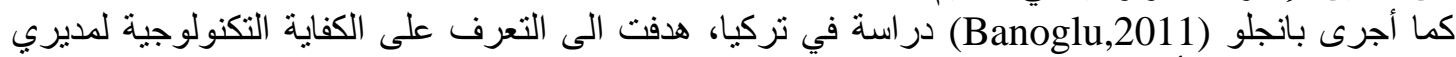
المدارس في تركيا وأثر ها على التحول نحو الإدارة المدرسية الإلكترونية، ثم اختيار عينة عشو التئية التئة من (134)

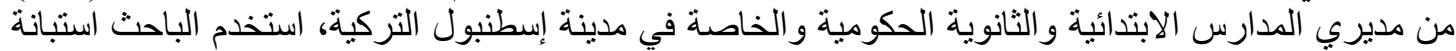

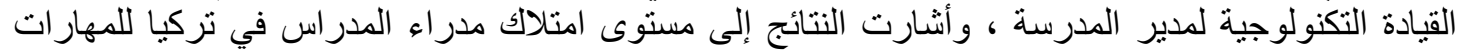

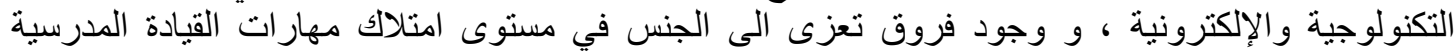
التكنولوجية لاى مدر اء المدر اس لصالح الصائ الإناث.

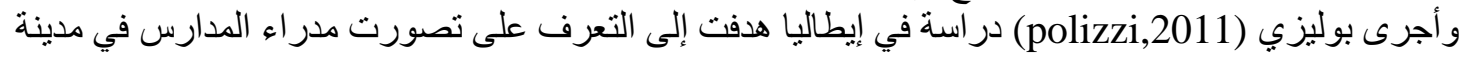

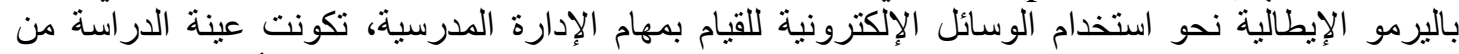

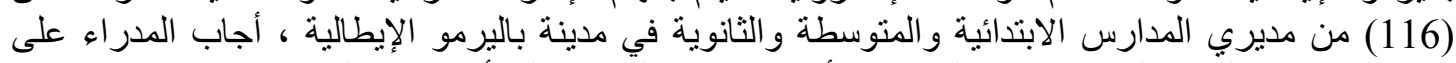

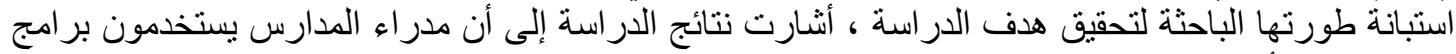

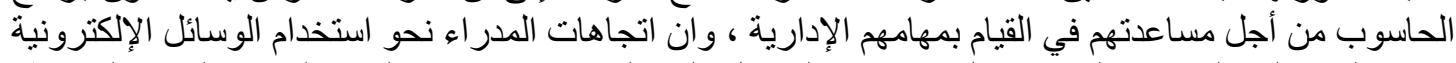

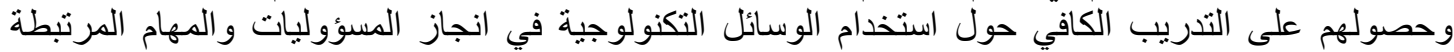

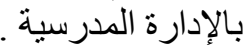
قام سرحان (Serhan,2007) بدراسة هدفت إلى التعرف على قياس فاعلية دورة تدريبية على التقنيات

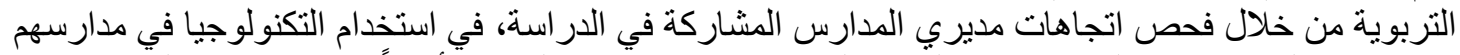

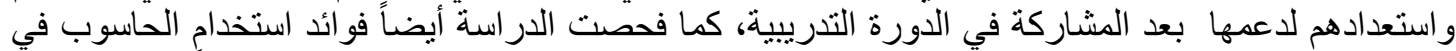

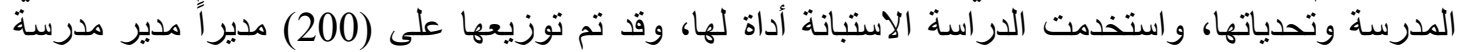

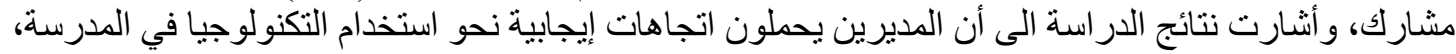

و هم على استعداد لدعمها في المدرسة.

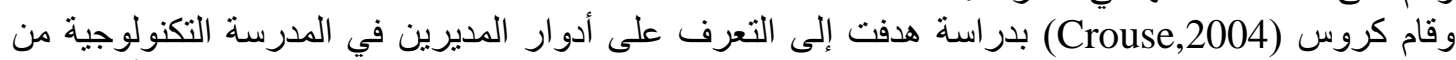

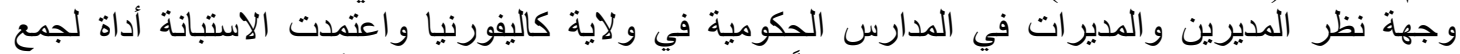

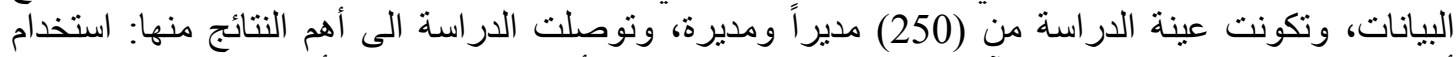

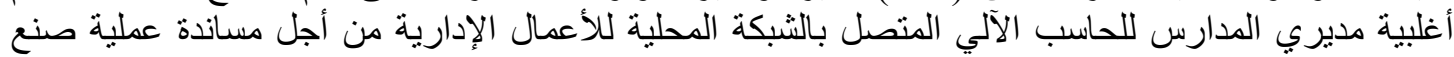

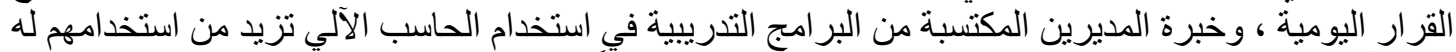

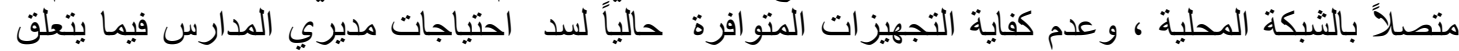

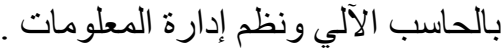
و أجرى فيلك (Felck,2010) دراسة في الو لايات المتحدة الأمريكية والتي هدفت اللى الكثنف عن مدى استخدام

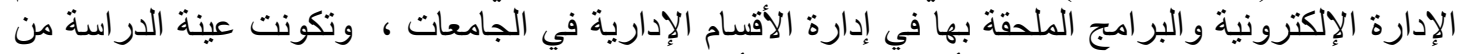

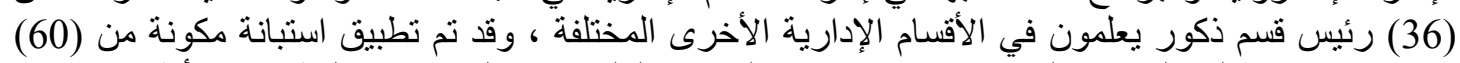

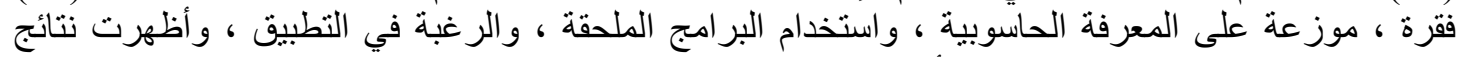

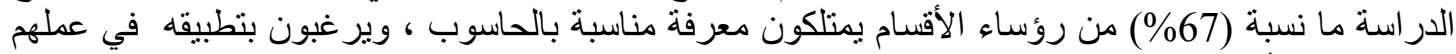

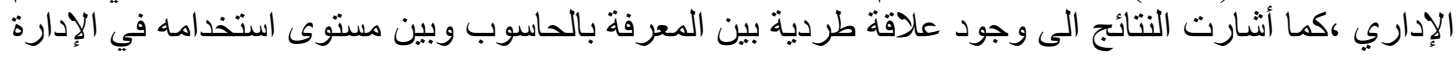




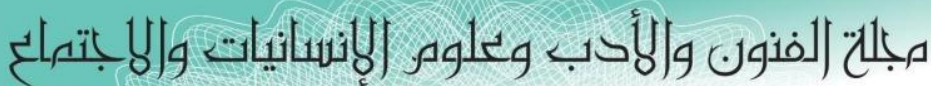

Journal of Arts, Literature, Humanities and Social Sciences

ISSN online: 2414 - 3383

ISSN print: 2616 - 3810

\section{العدد (43) أيلول - سبتمبر 2019}

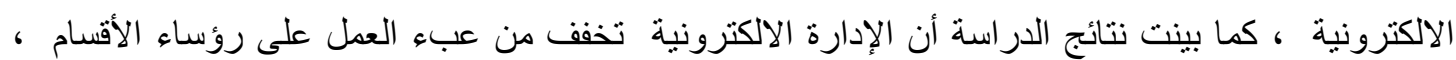

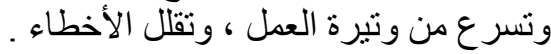

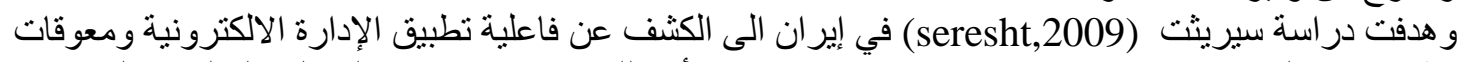

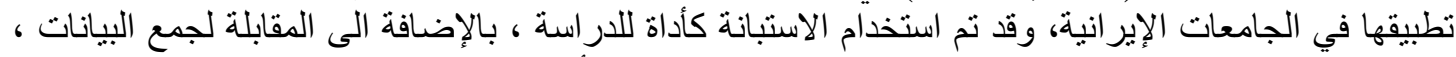

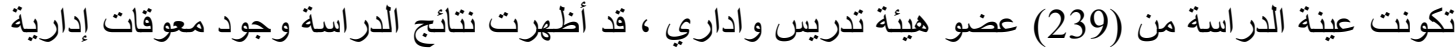

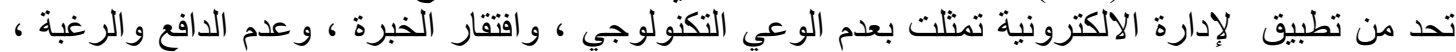

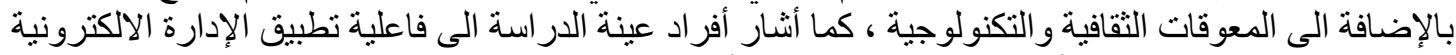

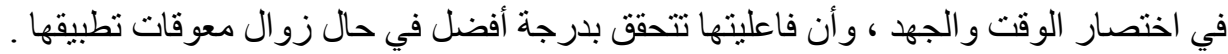

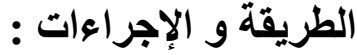

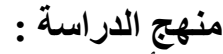

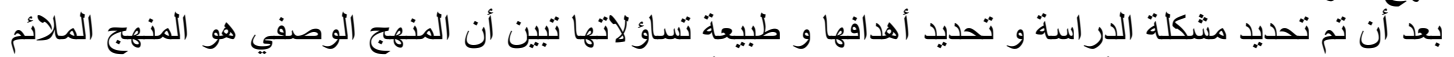

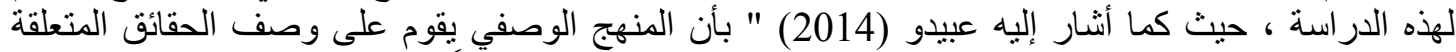
بطبيعة الظاهرة أو المادة موضوع البحث ، مع محاولة تفسير هذه الحقائق وفقاً للمعايير و الأسس العلمية .

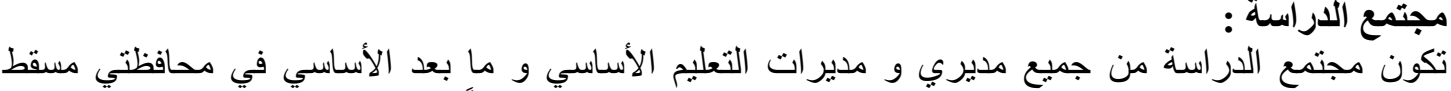

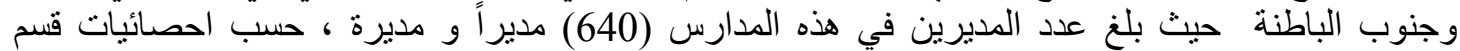

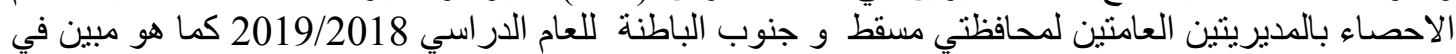

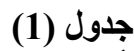

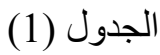

توزيع أفراد مجتمع الدراسة لمديري مدارس التعليم الأساسي و ما بعد الأساسي للمديرية العامة للتربية و التعليم في

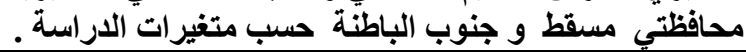

\begin{tabular}{|c|c|c|c|c|}
\hline الاجمالي & النسبة \% & العدد & الفئات & المتغير \\
\hline \multirow{2}{*}{640} & 45,31 & 290 & ذكر & \multirow{2}{*}{ الجنس } \\
\hline & 54,69 & 350 & أنتى & \\
\hline \multirow[b]{3}{*}{640} & 24,06 & 154 & 5-5 سنوات & \multirow{3}{*}{ سنو ات الخبرة } \\
\hline & 42,19 & 270 & 6-10سنوات & \\
\hline & 33,75 & 216 & 11 1سنة فأكثر & \\
\hline \multirow{3}{*}{640} & 60,93 & 390 & بكالوريوس & \multirow{3}{*}{ المؤهل العلمي } \\
\hline & 32,81 & 210 & بكالوريوس + دبلوم & \\
\hline & 06,26 & 40 & ماجستير & \\
\hline
\end{tabular}

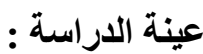

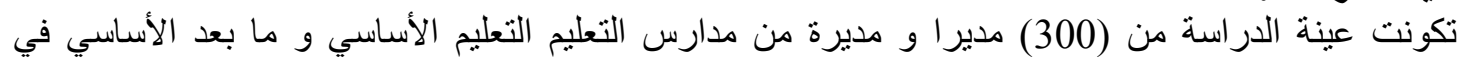

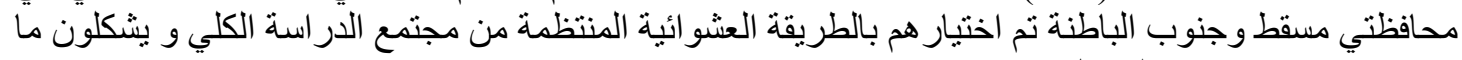
نسبته $(46,88)$ و ييين الجدول (2) 


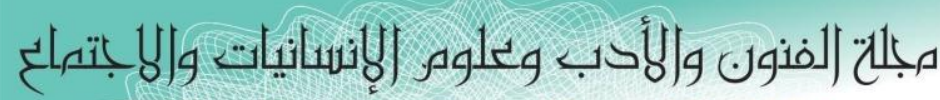
Journal of Arts, Literature, Humanities and Social Sciences

ISSN online: 2414 - 3383

ISSN print: 2616 - 3810

\section{العدد (43) أيلول -سبتهبر 2019}

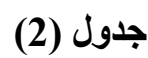

توزيع أفراد عينة الدراسة لمديري و مديرات مدارس التعليم الأساسي و ما بعد الأساسي في محافظتي مسقط وجنوب الباطنة حسب متغيرات الدراسة التئة

\begin{tabular}{|c|c|c|c|c|}
\hline الإجمالي & النسبة & 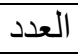 & 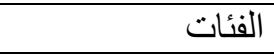 & المتغير | - لمير \\
\hline \multirow{2}{*}{300} & $\% 43,33$ & 130 & ذكر & \multirow{2}{*}{ 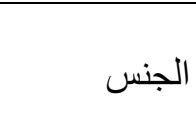 } \\
\hline & $\% 56,67$ & 170 & أنظى & \\
\hline \multirow{3}{*}{300} & $\% 21,67$ & 65 & 5-1 5-1 سنوات & \multirow{3}{*}{ سنو ات الخبرة } \\
\hline & $\% 45,00$ & 135 & 10-6 سنوات & \\
\hline & $\% 33,33$ & 100 & 11 سنة فأكثر & \\
\hline \multirow[b]{3}{*}{300} & $\% 70,00$ & 210 & بكالوريوس & \multirow{3}{*}{ المؤهل العلمي } \\
\hline & $\% 20,00$ & 60 & بكالوريوس + دبلوم & \\
\hline & $\% 10,00$ & 30 & ماجستير & \\
\hline 300 & $\% 100$ & 300 & & المجموع الكلي \\
\hline
\end{tabular}

و جاء مجال المنطلبات المالبة في المرتبة الثانية بمنوسط حسابي بلغ (3,73) و بإنحر اف معياري (0,83) و

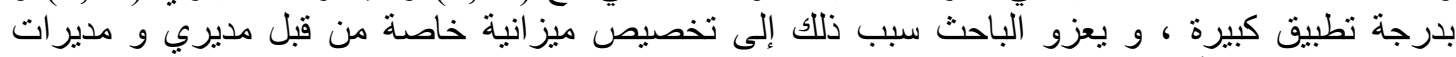

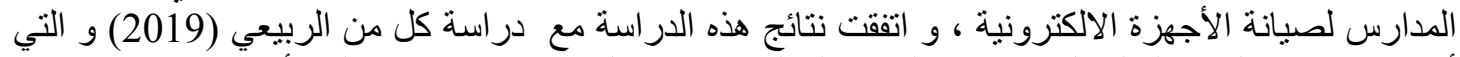

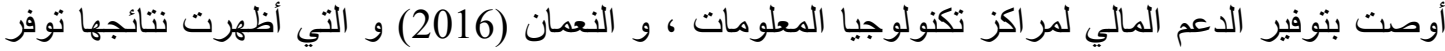

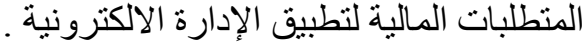

\section{عرض مناقثة النتائج

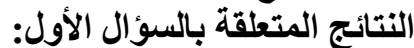

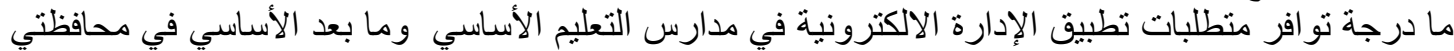

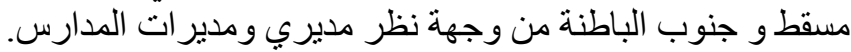

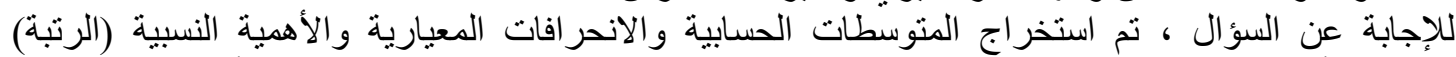

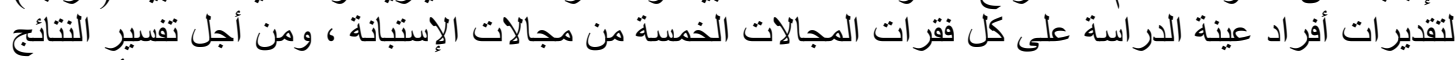

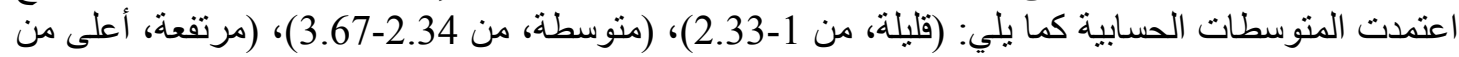

ويوضح الجدول (4) المتوسطات الحسابية و الانحر افات المعيارية والأهية النسبية (الرتبة) لتقدير ات أفراد عينة الدر اسة في مجالات الدر اسة الخمسة وفق قيمة المتوسط الحسابي لكل مجال.

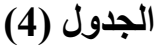

المتوسطات الحسابية والانحرافات المعيارية والأهمية النسبية (الرتبة) لتقديرات أفراد عينة الاراسة على

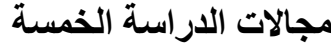

\begin{tabular}{|c|c|c|c|c|c|}
\hline الدرجة & الرتبة & الالنحراف & الحسابي & المجال & s \\
\hline كبيرة & 3 & 0.80 & 3.70 & المتطلبات البشرية والفنية & 1 \\
\hline
\end{tabular}




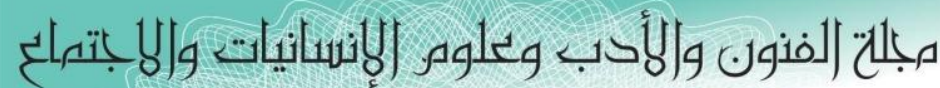

Journal of Arts, Literature, Humanities and Social Sciences

ISSN online: 2414 - 3383

ISSN print: 2616 - 3810

العدد (43) أيلول - سبتهبر 2019

\begin{tabular}{|c|c|c|c|c|c|}
\hline متوسطة & 5 & 0.86 & 3.32 & المتطلبات الإدارية & 2 \\
\hline كبيرة & 1 & 0.79 & 3.82 & المتطلبات المادية & 3 \\
\hline متوسطة & 4 & 0.92 & 3.38 & متطلبات السلامة و الأمن & 4 \\
\hline كبيرة & 2 & 0.83 & 3.73 & المتطلبات المالية & 5 \\
\hline كبيرة & & 0.77 & 3.75 & الدرجة الكلية & \\
\hline
\end{tabular}

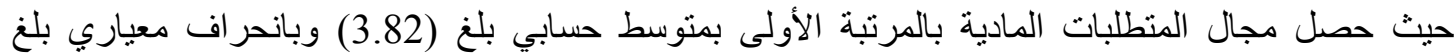

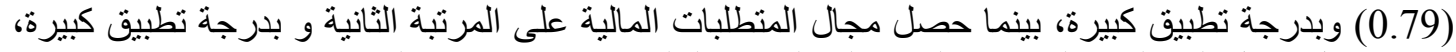

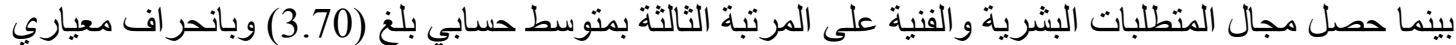

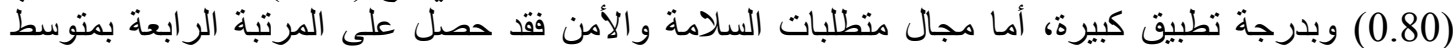

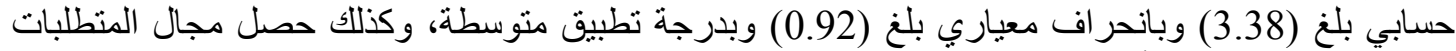
الإدارية في المرتبة الأخيرة بمتوسط حسابي بلغ (32.32) وبانحراف معياري بلغ (0.86) وبدرجة نطبيق متوسطة.

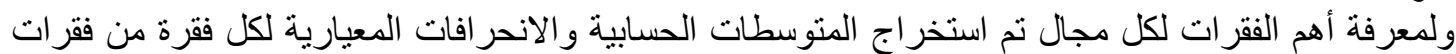

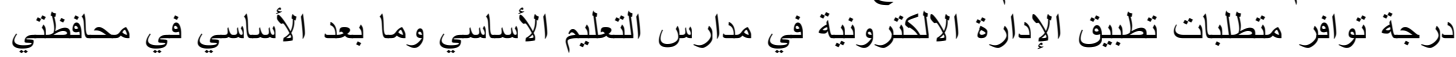

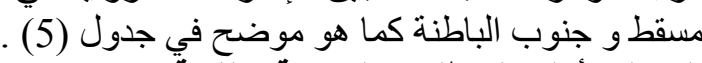
المجال الأول: المتطلبات البشرية والفنية

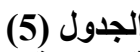

المتوسطات الحسابية والاتحرافات المعيارية والأهمية النسبية (الرتبة) على فقرات المجال الأول والمتطلبات البشرية و والفنية.

\begin{tabular}{|c|c|c|c|c|c|}
\hline الدرجة & 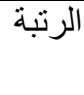 & المعياري & الحستيط & 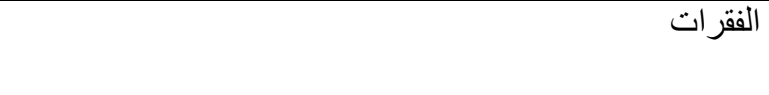 & 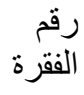 \\
\hline متوسطة & 6 & 0.62 & 3.17 & تستخدين إدارة المدرسة بمدربين مؤ هلين لتدريب العاملين على المعلى & 1 \\
\hline كبيرة جدا & 1 & 0.80 & 4.06 & تمتلك إدارة المدرسة مهار ات استخدام الحاسوب & 2 \\
\hline متوسطة & 5 & 0.66 & 3.35 & الالكترونية في المدرسة فنيون قادرون على صبانة الأجهزة & 3 \\
\hline 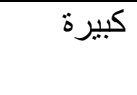 & 3 & 0.73 & 3.70 & الالكترونية إدارة المدرسة الوعي بين العاملين بأهمية الإدارة & 4 \\
\hline
\end{tabular}




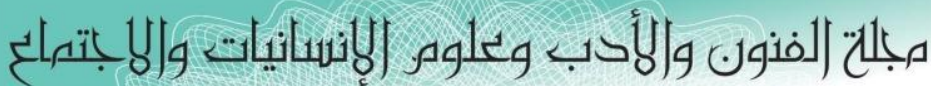

Journal of Arts, Literature, Humanities and Social Sciences

ISSN online: 2414 - 3383

ISSN print: 2616 - 3810

العدد (43) ايلول - سبتهبر 2019

LALHSS

WWw.jalhss.com

\begin{tabular}{|c|c|c|c|c|c|}
\hline كبيرة & 2 & 0.75 & 3.71 & e-mail تستخدم إدارة المدرسة البريد الالكتروني & 5 \\
\hline متوسطة & 7 & 0.61 & 3.08 & للأعمال الإدارية فية المدسة مبرمجون لتصميم البرامج الالكترونية & 6 \\
\hline كبيرة & 4 & 0.73 & 3.68 & تالتجديد في أسارة المدرسة للتحول إلى الإدارة الالكترونية من خلال & 7 \\
\hline كبيرة & & 0.71 & 3.73 & الدرجة الكلية & \\
\hline
\end{tabular}

يبين الجدول (5) أن المتوسطات الحسابية قد تراوحت ما بين (3.08-4.06) حيث جاءت الفقرة (2) و التي نصت (لإت

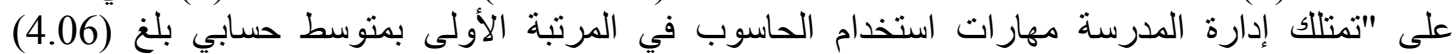

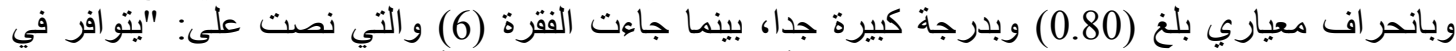

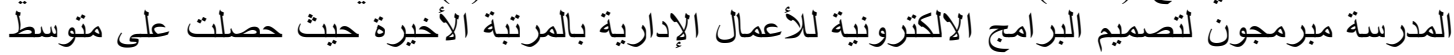

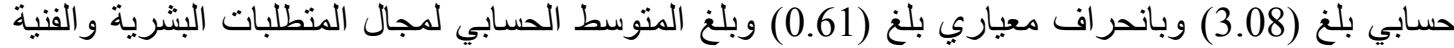

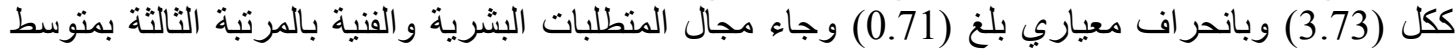

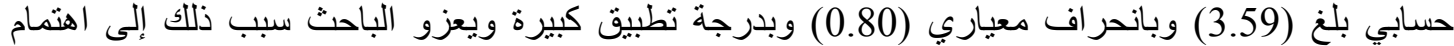

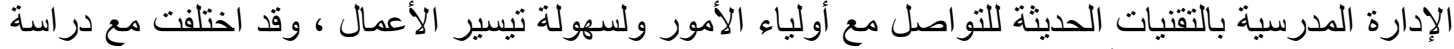
(Seresht,2009) و التي أظهرت نتائج الدراسة وجود معوقات إدارية تحد من تطبيق الإدارة الالكترونية تمثلت بعدم الوعي التكنولوجي و افتقار الخبرة. وكذلك يعزو الباحث سبب ذلك إلى الهتمام الإدارة بالقدرات والامكانيات المنوفرة في المدرسة دون الاستعانة

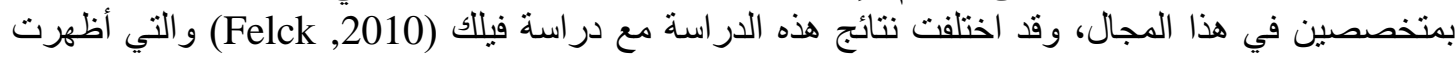

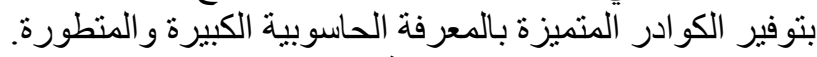
المجال الثاني: المتطلبات الإدارية المئية يوضح الجدول (6) المنوسطات الحسايية والانحر افات الإلية المعيارية والأهمية النسبية (الرتبة) لتقدير ات أفراد عينة

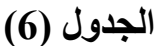
الدر اسة على فقر ات المجال الثناني: المتطلبات الإدارية الدية

المتوسطات الحسابية والانحر افات المعيارية والأهمية النسبية

\begin{tabular}{|c|c|c|c|c|c|}
\hline الدرجة & الرتبة & الانحر افياري & الحسابي & الفقر ات & 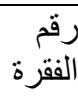 \\
\hline كبيرة & 3 & 0.72 & 3.70 & تمتاج إليها الإدارة المدرسة مهارة إلادارة الوقت التي & 8 \\
\hline متوسطة & 5 & 0.63 & 3.24 & تمتلإدارة إدارة المدرسة دليلا إجرائيا لتطبيق & 9 \\
\hline كبيرة & 1 & 0.77 & 3.75 & 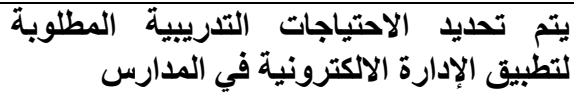 & 10 \\
\hline
\end{tabular}




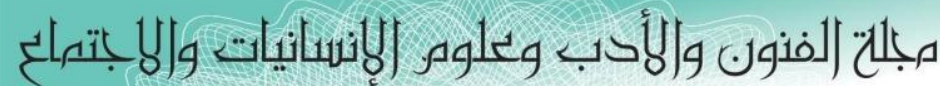

Journal of Arts, Literature, Humanities and Social Sciences

ISSN online: 2414 - 3383

ISSN print: 2616 - 3810

\section{العدد (43) أيلول - سبتمبر 2019}

¿ÁLHSS

www.jalhss.com

\begin{tabular}{|c|c|c|c|c|c|}
\hline متوسطة & 6 & 0.61 & 3.16 & تناسبة لتطبيق الإدارة الالكترونية عمل (مناخ تنظيمي) & 11 \\
\hline كبيرة & 2 & 0.71 & 3.73 & 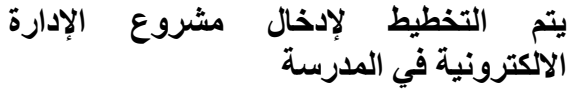 & 12 \\
\hline متوسطة & 7 & 0.60 & 3.08 & للشرجد تنسيق بين إدارة المدرسة والإدارة العليا & 13 \\
\hline متوسطة & 4 & 0.64 & 3.25 & خدمتاتها عن طرة المديق الشبكة خطة العنكبوتية اتيجية لتقديم & 14 \\
\hline متوسطة & & 0.69 & 3.34 & الارجة الكلية & \\
\hline
\end{tabular}

يبين الجدول (6) أن المتوسطات الحسابية قد تراوحت ما بين (3.08-3.75)، حيث جاءت الفقرة (10) و التي الإبي

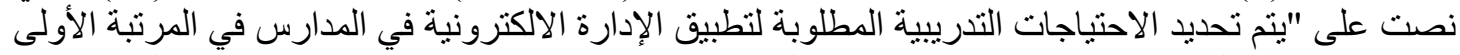

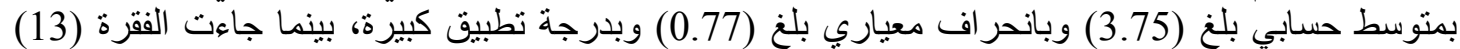

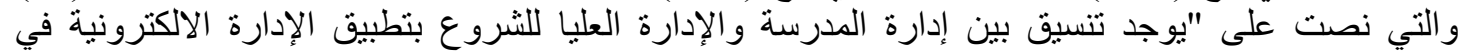

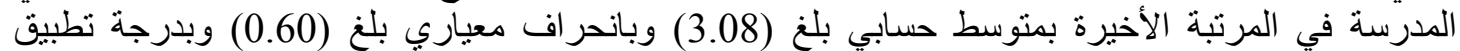

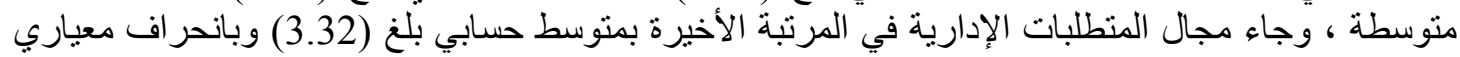

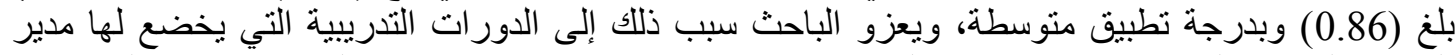

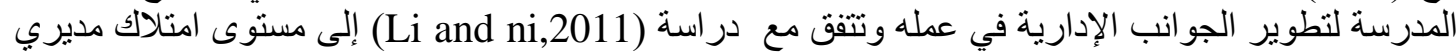

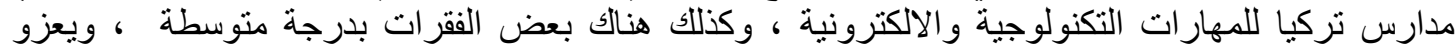

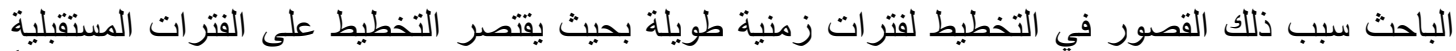
وتتفق هذه الدر اسة مع در اسة كروس (Crouse,2004) و التي أشنارت إلى عدم كفاية التجهيزات المتو افرة حالياً

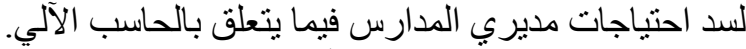

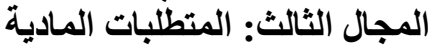

ويوضح الجدول (7) المتوسطات الحسابية والانحر افات المعيارية والأهمية النسبية لتقدير ات أفر اد عينة الدراسة

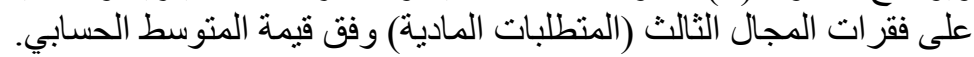

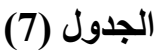

المتوسطات الحسابية والانحرافات المعيارية والأهمية النسبية لتقيرات أفراد عينة الدراسة على فقرات المجال

\begin{tabular}{|c|c|c|c|c|c|}
\hline الدرجة & الرتبة & 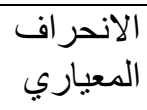 & 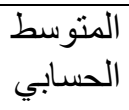 & الفقرات & الفقرة \\
\hline كبيرة جداً & 2 & 0.80 & 4.08 & تمتبكة العنكبرتية موقع الكتروني على & 15 \\
\hline كبيرة جداً & 1 & 0.86 & 4.17 & إنجاز الأعمال الإدارية جازة هاتف يستخدم في & 16 \\
\hline
\end{tabular}




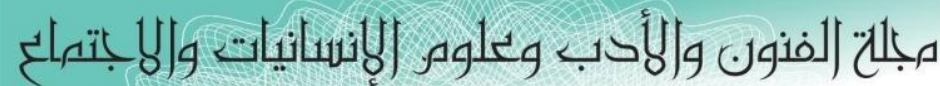

Journal of Arts, Literature, Humanities and Social Sciences

ISSN online: 2414 - 3383

ISSN print: 2616 - 3810

\section{العدد (43) أيلول - سبتمبر 2019}

LALHSS

WWw.jalhss.com

\begin{tabular}{|c|c|c|c|c|c|}
\hline كبيرة & 5 & 0.73 & 3.71 & لتطبيق الإدارة الالكترونية الحية المدرسة مناسب & 17 \\
\hline كبيرة جداً & 3 & 0.79 & 4.03 & وأولياء أمور الطاتبة الأكتروني بين المدرسة & 18 \\
\hline متوسطة & 6 & 0.71 & 3.46 & لالادى المدرسة بلاركترونية جاهزة خاصة بتطبيق & 19 \\
\hline كبيرة & 4 & 0.74 & 3.76 & تثاليةترك المدرسة بخط (ADSL) ذو سرعة & 20 \\
\hline كبيرة & & 0.78 & 3.82 & الارجة الكلية & \\
\hline
\end{tabular}

وييين الجدول (7) أن المتوسطات الحسابية قد تراوحت ما بين (3.46-4.17)، حيث جاءت الفقرة (16) والتي الإني

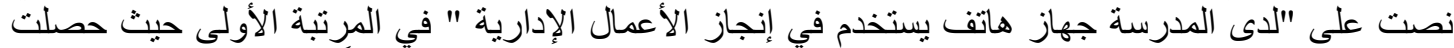

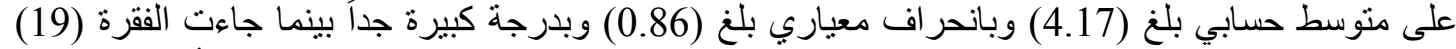

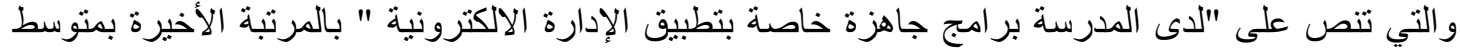

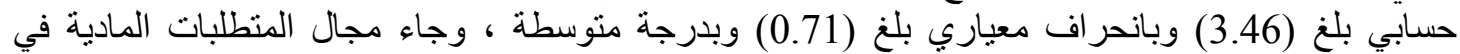

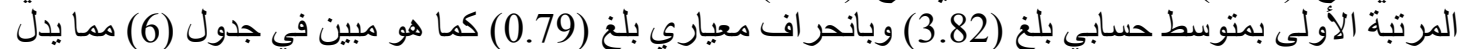

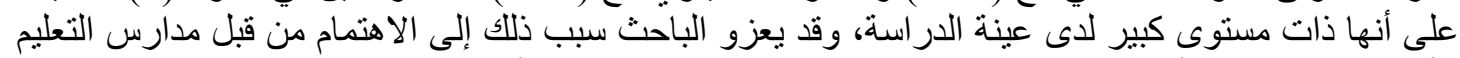

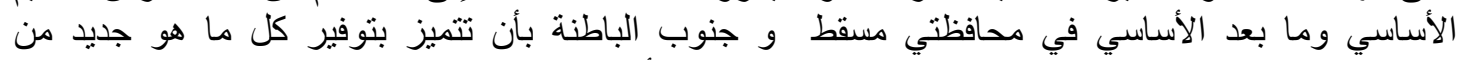

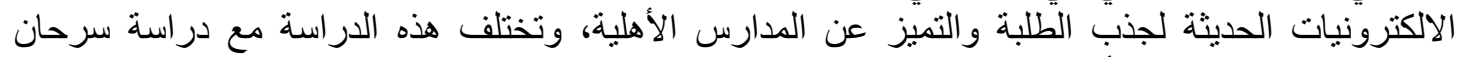
(Serhan,2009)

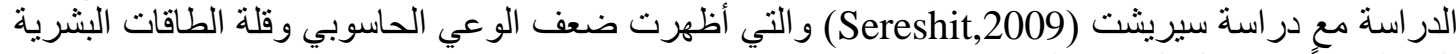
المؤهلة فنياً في مجال التقنية الالكترونية.

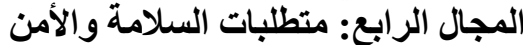

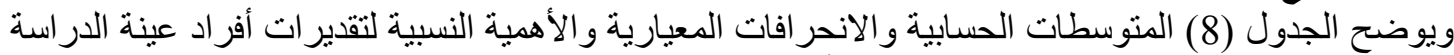

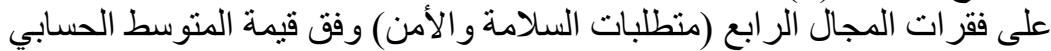

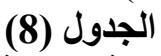

المتوسطات الحسابية والاتحر افات المعيارية والأهمية النسبية لتقديرات أفراد عينة الدراسة على فقرات المجال

\begin{tabular}{|c|c|c|c|c|c|}
\hline الدرجة & الرتبة & 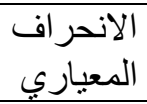 & الحسابي & الفقرات & رالفرة \\
\hline متوسطة & 4 & 0.65 & 3.12 & بيانتات المدرسة أنظمة حماية آلية متطورة لحماية & 21 \\
\hline كبيرة & 1 & 0.78 & 3.77 & توالة تلفها أو تعطتل الحاسبات الآلية البيانات في & 22 \\
\hline متوسطة & 5 & 0.67 & 3.09 & 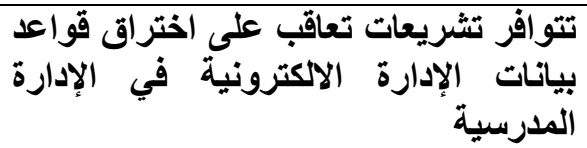 & 23 \\
\hline
\end{tabular}




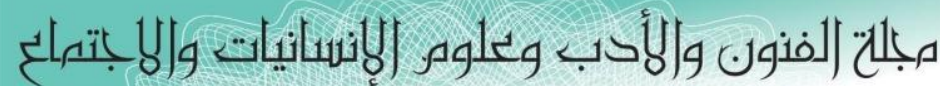

Journal of Arts, Literature, Humanities and Social Sciences

ISSN online: 2414 - 3383

ISSN print: 2616 - 3810

\section{العدد (43) أيلول - سبتهبر 2019}

¿ALLHSS

WWw.jalhss.com

\begin{tabular}{|c|c|c|c|c|c|}
\hline كبيرة & 2 & 0.76 & 3.72 & 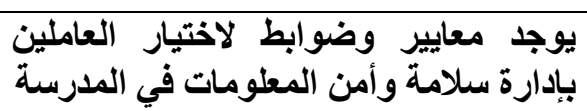 & 24 \\
\hline منوسطة & 3 & 0.65 & 3.13 & 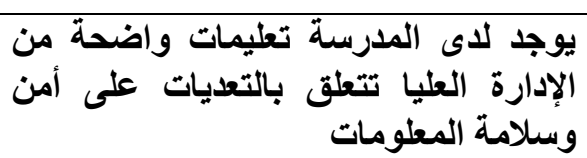 & 25 \\
\hline متوسطة & & 0.70 & 3.40 & الارجة الكلية & \\
\hline
\end{tabular}

ويبين الجدول (8) أن المتوسطات الحسابية قد تراوحت ما بين (3.09-3.77)، حيث جاءت الفقرة (22) والتي التي

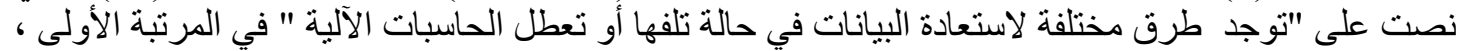

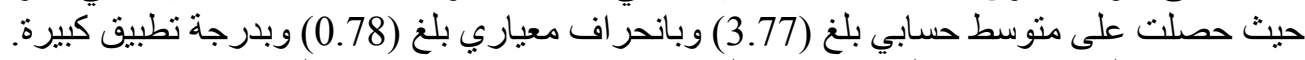

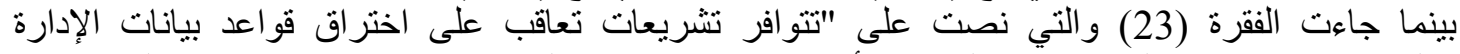

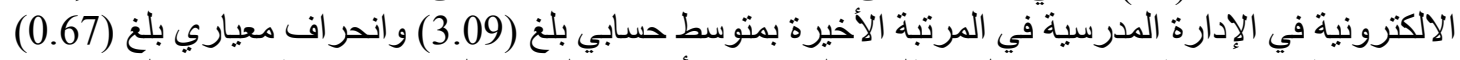

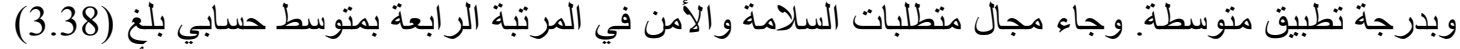

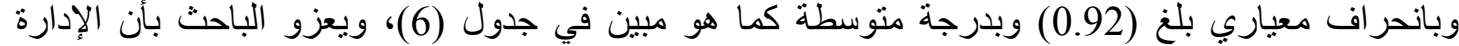

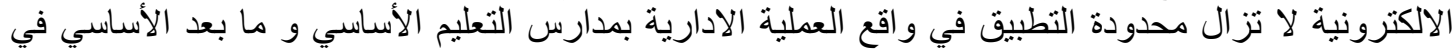

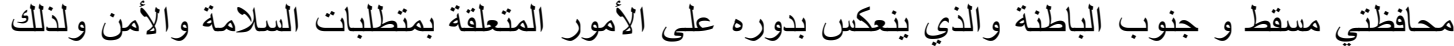
جاءت درجة تطبيقها ما بين المتوسطة و الكبيرة.

المجال الخامس: المتطلبات المالية ويوضح الجدول (9) المنوسطات الحسابية والانحر افات المات المعيارية و الأهمية النسبية لتقدير ات أفر اد عينة الدراسة

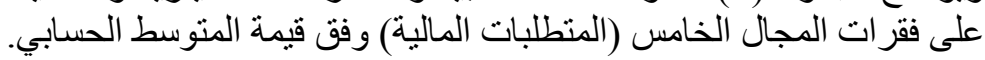
(9) الجدول

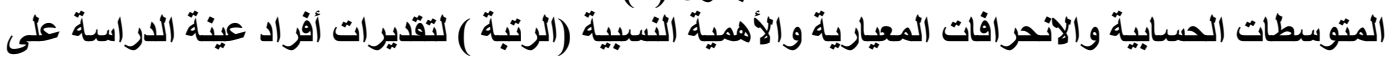
فقرات المجال الخامس (المنطلبات المالية) وفق قيمة المتية المتوسط الحسابي.

\begin{tabular}{|c|c|c|c|c|c|}
\hline الدرجة & الرتبة & المعياري الانحر اف & الحسابي & الفقر ات & الفقرة \\
\hline كبيرة & 1 & 0.75 & 3.96 & تلتصميم و إدارة المدرير البرامج الاكترونية الأموال اللازمة & 26 \\
\hline كبيرة & 2 & 0.79 & 3.88 & لتوفير البيئة التحتية للإدارة الاكتئرونية اللدالية الكافي & 27 \\
\hline كبيرة & 4 & 0.76 & 3.67 & 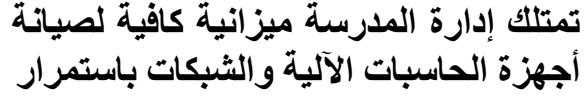 & 28 \\
\hline كبيرة & 5 & 0.78 & 3.65 & 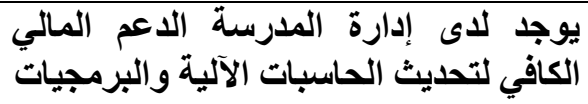 & 29 \\
\hline كبيرة & 3 & 0.77 & 3.78 & 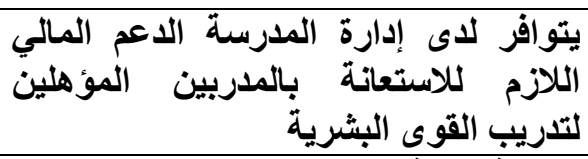 & 30 \\
\hline كبيرة & & 0.76 & 3.75 & الارجة الكلية & \\
\hline
\end{tabular}




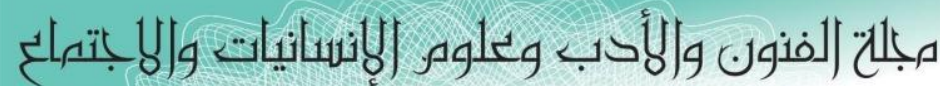

Journal of Arts, Literature, Humanities and Social Sciences

ISSN online: 2414 - 3383

ISSN print: 2616 - 3810

\section{العدد (43) أيلول - لسبتمبر 2019}

ويوضح الجدول (9) أن المتوسطات الحسابية قد تراوحت ما بين (3.65-3.96)، حيث جاءت الفقرة (26) والتي

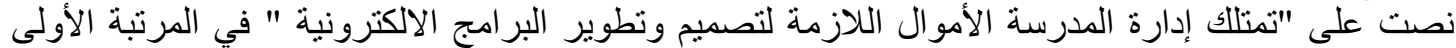

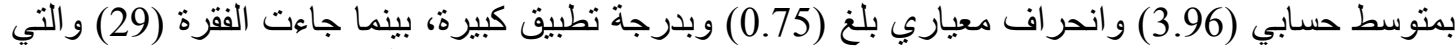

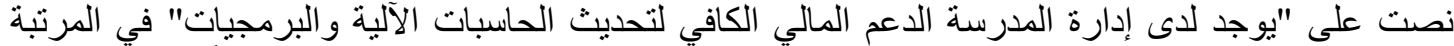

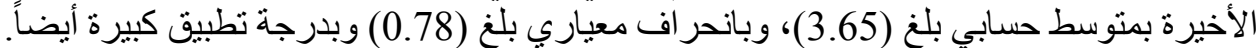

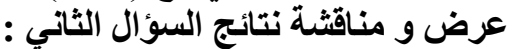

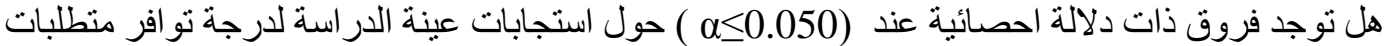

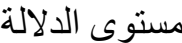
الادارة الالكترونية في مدارس التعليم الأساسي و مابعد الأساسي في محافظتي مسقط وجنوب الباطنة؟

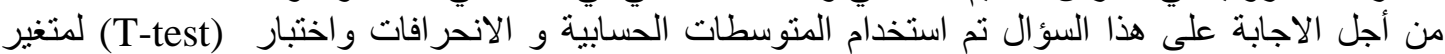
الجنس. بالنسبة لمتغير الجنس : الجنول

حيث يوضبح الجدول (10) المتوسطات الحسابية و الاتحرافات المعيارية واختبار T-test بالنسبة للجنس

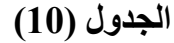

المتوسطات الحسابية و الانحرافات المعيارية واختبار T-test للدجة توافر متطبات الإبات الادارة الاكترونية في مدارس

\begin{tabular}{|c|c|c|c|c|c|c|c|}
\hline الدسلةى & قيمة ت & الانحياري اف & الحسابية & العدد & الجنس & المجال & رق \\
\hline \multirow[t]{3}{*}{0,45} & 0,71 & 1,14 & 2,39 & 130 & ذكر & \multirow{3}{*}{ المتطلبات البشرية و الفنية } & \multirow{3}{*}{1} \\
\hline & & & & & & & \\
\hline & & 0,93 & 2,32 & 170 & أنثى & & \\
\hline \multirow[t]{2}{*}{0,53} & 0,83 & 0,94 & 2,22 & 130 & ذكر & \multirow[t]{2}{*}{ المنطلبات الإدارية } & \multirow[t]{2}{*}{2} \\
\hline & & 0,96 & 2,05 & 170 & أنثى & & \\
\hline \multirow[t]{2}{*}{0,52} & 1,48 & 0,92 & 2,92 & 130 & ذكر & \multirow[t]{2}{*}{ المتطلبات المادية } & \multirow[t]{2}{*}{3} \\
\hline & & 1,24 & 2,47 & 170 & أنثى & & \\
\hline \multirow[t]{2}{*}{0,48} & 1,01 & 0,74 & 1,50 & 130 & ذكر & \multirow[t]{2}{*}{ متطلبات السلامة و الأمن } & \multirow[t]{2}{*}{4} \\
\hline & & 0,75 & 1,72 & 170 & أنثى & & \\
\hline \multirow[t]{2}{*}{0,04} & 1,02 & 1,05 & 2,04 & 130 & ذكر & \multirow[t]{2}{*}{ المتطلبات المالية } & \multirow[t]{2}{*}{5} \\
\hline & & 1,24 & 2,10 & 170 & أنثى & & \\
\hline \multirow[t]{2}{*}{0,08} & 1,66 & 1,00 & 2,23 & 130 & ذكر & \multirow[t]{2}{*}{ الدرجة الكلية } & \\
\hline & & 1,22 & 2,36 & 170 & أنتى & & \\
\hline
\end{tabular}




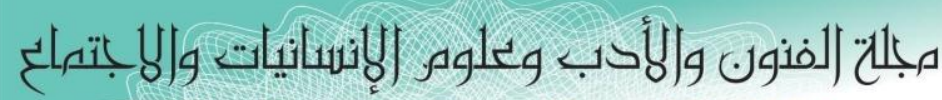
Journal of Arts, Literature, Humanities and Social Sciences

\section{ISSN online: 2414 - 3383 \\ ISSN print: 2616 - 3810 \\ العدد (43) أيلول - سبتمبر 2019}

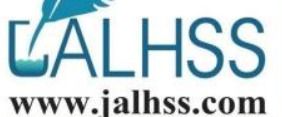

www.jalhss.com

(

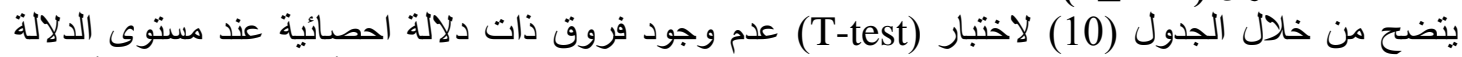

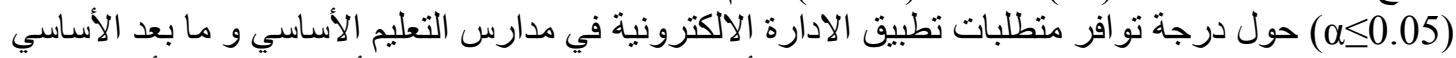

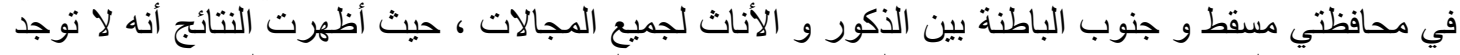

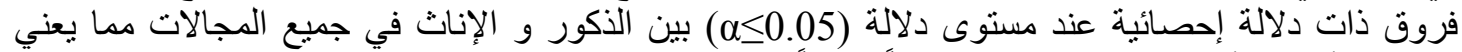

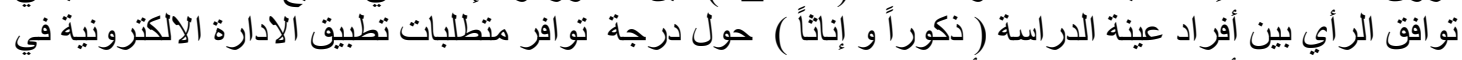

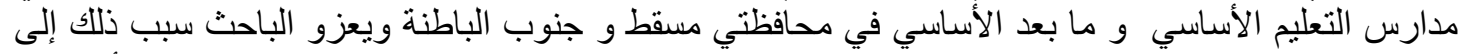

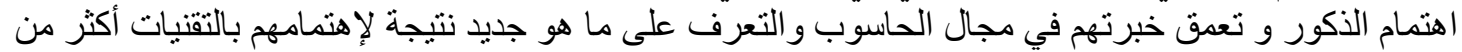

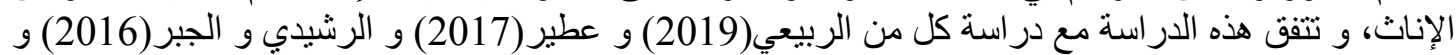

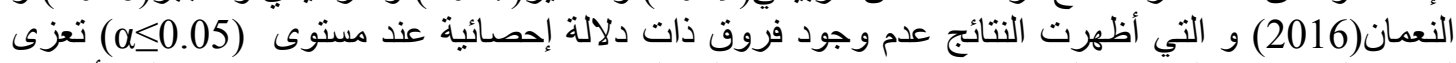

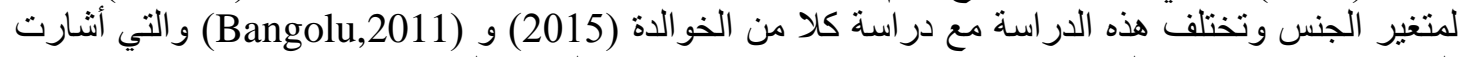

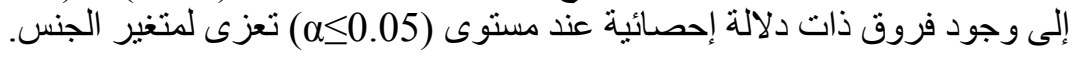

متغير المؤهل العلمي (بكالوريوس ، بكالوريوس +دبلوم ، ماجستير )

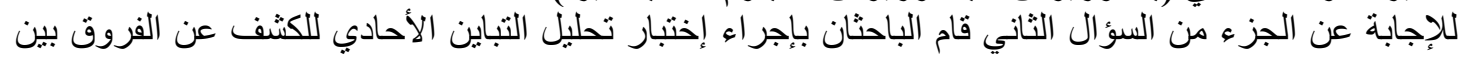

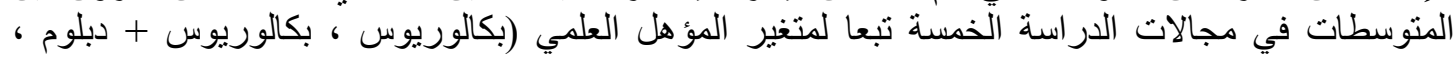

ماجستير ) ، و جاءت النتائج على النحو الموضح في الجدول (11) .

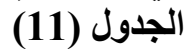

نتائج اختبار تحليل التباين الأحادي للكشف عن دلالة الفروق بين المتوسطات الحسابية لمجالات الاراسة

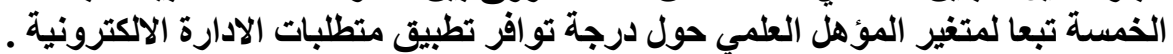

\begin{tabular}{|c|c|c|c|c|c|c|c|c|c|}
\hline مستوى & الإلدصائية & قيمة & الحرجة & المربعات & المربعوع & مصدر التباين & & المجالات & 5 \\
\hline \multirow{3}{*}{ غير } & \multirow{3}{*}{0,74} & \multirow{3}{*}{0,30} & 2 & 0,07 & 0,14 & الينحو عات & \multirow{3}{*}{9} & \multirow{3}{*}{ الفنشية الفنبة } & \multirow[t]{3}{*}{1} \\
\hline & & & 99 & 0,23 & 23,03 & داخل ـــ ـ ـ & & & \\
\hline & & & 101 & & 23.17 & المجمو ع & & & \\
\hline \multirow{5}{*}{ غير } & \multirow{5}{*}{0,85} & \multirow{5}{*}{0,15} & 2 & 0,03 & 0,07 & بين & \multirow{5}{*}{\multicolumn{2}{|c|}{ الادارية }} & \multirow[t]{5}{*}{2} \\
\hline & & & & & & المجمو عات & & & \\
\hline & & & 99 & 0,23 & 23,00 & داخل & & & \\
\hline & & & & & & المجمو عات & & & \\
\hline & & & 101 & & 23,07 & المجموع & & & \\
\hline \multirow{5}{*}{ غالة } & \multirow[t]{5}{*}{0,15} & \multirow[t]{5}{*}{1,92} & 2 & 0,41 & 0,82 & & \multirow{5}{*}{\multicolumn{2}{|c|}{ المادية البات }} & \multirow[t]{5}{*}{3} \\
\hline & & & & & & المجمو عات & & & \\
\hline & & & 99 & 0,21 & 21,11 & داخل & & & \\
\hline & & & & & & المجمو عات & & & \\
\hline & & & 101 & - & 28,88 & المجموع & & & \\
\hline \multirow{3}{*}{ غير } & \multirow[t]{3}{*}{0,09} & \multirow[t]{3}{*}{2,47} & 2 & 0,68 & 21,11 & & \multirow{3}{*}{9} & منطلبات & \multirow[t]{3}{*}{4} \\
\hline & & & & & & المجمو عات & & السلامة & \\
\hline & & & 99 & 0,27 & 01,37 & المجمو عاتل & & الأمن & \\
\hline
\end{tabular}


مبلحة (لفنون والأدب وعلوه الإنسانيات واله بتهماع Journal of Arts, Literature, Humanities and Social Sciences

ISSN online: 2414 - 3383

ISSN print: 2616 - 3810

العدد (43) ايلول - سبتمبر 2019

LALHSS

www.jalhss.com

\begin{tabular}{|c|c|c|c|c|c|c|c|c|}
\hline & & & 101 & - & 22,48 & المجموع & & \\
\hline \multirow{5}{*}{ غالة } & \multirow[t]{5}{*}{0,37} & \multirow[t]{5}{*}{1,81} & 2 & 0,04 & 1,37 & بين & \multirow{5}{*}{ الماليةلبات } & \multirow[t]{5}{*}{5} \\
\hline & & & & & & المجمو عات & & \\
\hline & & & 99 & 0,23 & 27,51 & داخل & & \\
\hline & & & & & & المجمو عات & & \\
\hline & & & 101 & - & 28,88 & المجموع & & \\
\hline \multirow{5}{*}{ غالة } & \multirow[t]{5}{*}{0,65} & \multirow[t]{5}{*}{2,45} & 2 & 0,51 & 01,25 & بين & \multirow[t]{5}{*}{ الدرجة الكلية } & \\
\hline & & & & & & المجمو عات & & \\
\hline & & & 99 & 0,38 & 26,45 & داخل & & \\
\hline & & & & & & المجمو عات & & \\
\hline & & & 101 & - & 27,70 & المجموع & & \\
\hline
\end{tabular}

يتضح من الجدول (11) أنه لبست هناك فروقاً دالة إحصائياً بين متوسطات المجالات الخمسة التى تثملها

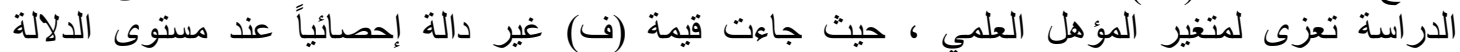

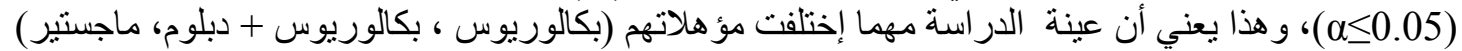

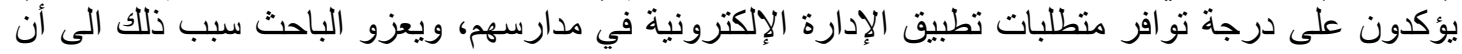

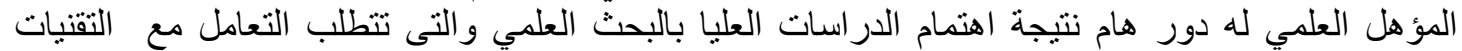

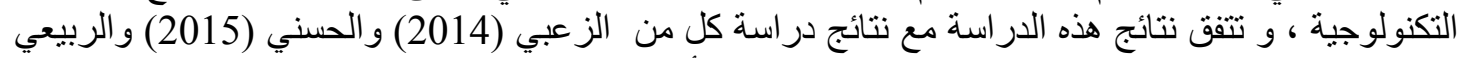

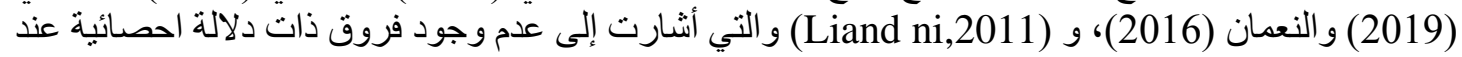

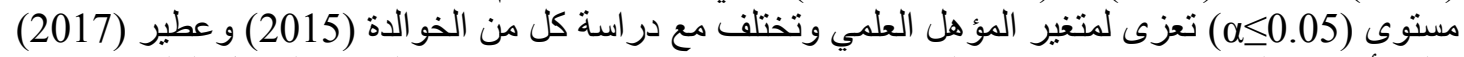

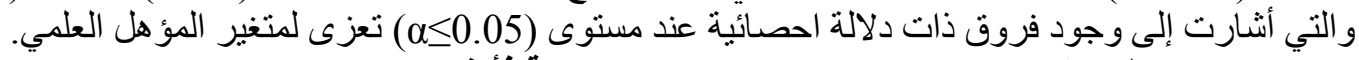

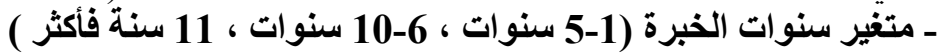

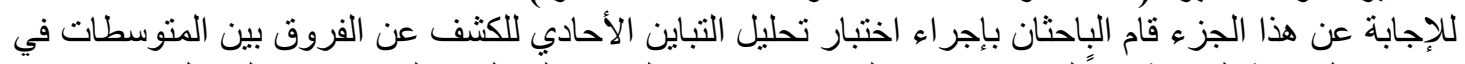

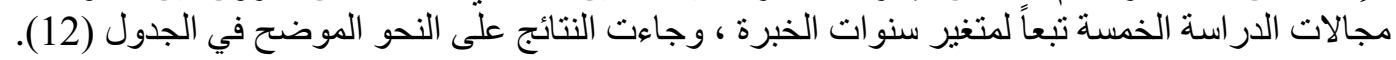

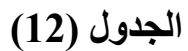

نتائج اختبار تحليل التباين الأحادي للكثف عن دلالة الفروق بين المتوسطات الحسابية لمجالات الدراسة الخمسة تبعا لمتغير سنوات الخبرة.

\begin{tabular}{|c|c|c|c|c|c|c|c|c|}
\hline مستوى الدلالة & الإحصسائية & قفيمة & المربعات & المربعوع & الحرجة & التباين & المجالات & 5 \\
\hline \multirow[t]{3}{*}{ غير دالة } & \multirow[t]{3}{*}{0,88} & \multirow[t]{3}{*}{1,17} & 1,10 & 02,20 & 2 & بين & \multirow{3}{*}{ البشتية النبات } & \multirow[t]{3}{*}{1} \\
\hline & & & 0,93 & 37,30 & 78 & داخل & & \\
\hline & & & - & 39,50 & 80 & المجموع & & \\
\hline \multirow[t]{2}{*}{ غير دالة } & \multirow[t]{2}{*}{0,12} & \multirow[t]{2}{*}{2,55} & 1,28 & 02,56 & 2 & بين & \multirow[t]{2}{*}{ الإدارية } & \multirow[t]{2}{*}{2} \\
\hline & & & 0,50 & 39,18 & 78 & المجمو عات & & \\
\hline
\end{tabular}




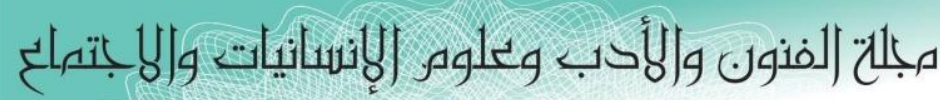
Journal of Arts, Literature, Humanities and Social Sciences

ISSN online: 2414 - 3383

ISSN print: 2616 - 3810

العدد (43) ايلول - سبتهبر 2019

\begin{tabular}{|c|c|c|c|c|c|c|c|c|}
\hline & & & - & 41,74 & 80 & المجموع & & \\
\hline \multirow[t]{3}{*}{ غير دالة } & \multirow[t]{3}{*}{0,46} & \multirow[t]{3}{*}{2,82} & 1,41 & 02,81 & 2 & بين المحمو عات & \multirow[t]{3}{*}{ المادية } & \multirow[t]{3}{*}{3} \\
\hline & & & 0,50 & 38,12 & 78 & داخلمو عات & & \\
\hline & & & - & 40,93 & 80 & المجموع & & \\
\hline \multirow[t]{5}{*}{ غير دالة } & \multirow[t]{5}{*}{0,26} & \multirow[t]{5}{*}{2,43} & 1,26 & 02,25 & 2 & & \multirow{5}{*}{ الأمنامة و السطبات } & \multirow[t]{5}{*}{ 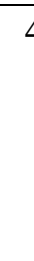 } \\
\hline & & & & & & المجمو عات & & \\
\hline & & & 0,46 & 36,10 & 78 & داخل & & \\
\hline & & & & & & المجمو عات & & \\
\hline & & & - & 38,35 & 80 & المجموع & & \\
\hline \multirow[t]{4}{*}{ غير دالة } & \multirow[t]{4}{*}{1,15} & \multirow[t]{4}{*}{2,83} & 1,24 & 02,48 & 2 & بين & \multirow{4}{*}{ المالية المتبات } & \multirow[t]{4}{*}{5} \\
\hline & & & 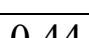 & 3420 & 78 & |广子 & & \\
\hline & & & 4,74 & 3,20 & 10 & المحمو عات & & \\
\hline & & & - & 36,68 & 80 & المجموع & & \\
\hline \multirow[t]{4}{*}{ غير دالة } & \multirow[t]{4}{*}{0,14} & \multirow[t]{4}{*}{2,43} & 1,25 & 02,51 & 2 & بين & \multirow{4}{*}{ الكلية } & \\
\hline & & & 0,52 & 40,30 & 78 & داخل & & \\
\hline & & & & & & المجمو عات & & \\
\hline & & & - & 42,81 & 80 & المجموع & & \\
\hline
\end{tabular}

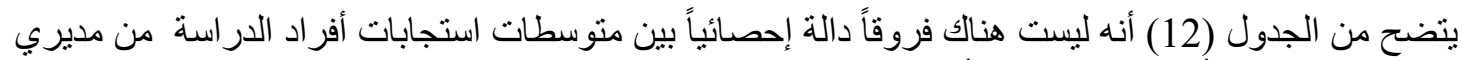

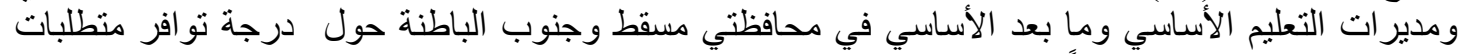

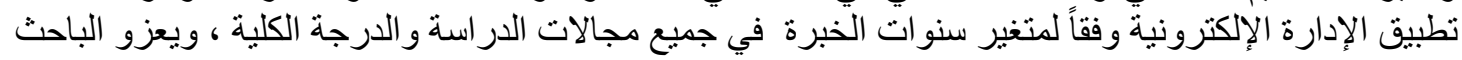

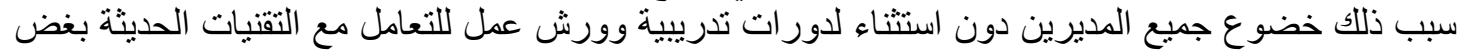
النظر عن مستوى الخبرة التى يمتلكونها ، وقد تتفق هذه الدراسة مع دراسة عطير (2015 (2017) و النعمان (2016)

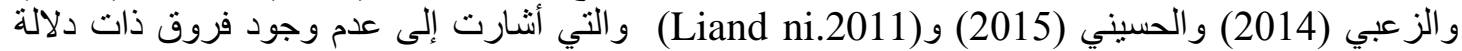

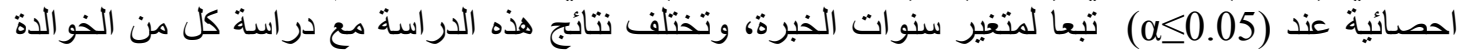
(2015)، الربيعي (2019) و الرشيدي والجبر (2016).

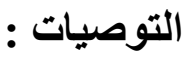

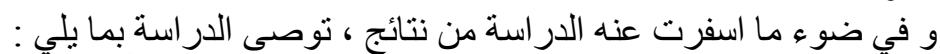

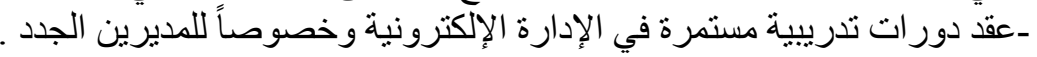

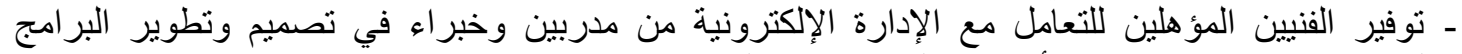

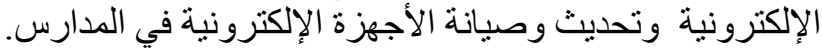
ـ عقد دور ات تدريية لجميع العاملين في المدرسة لتطبيق الإدارة الإلكترونية 


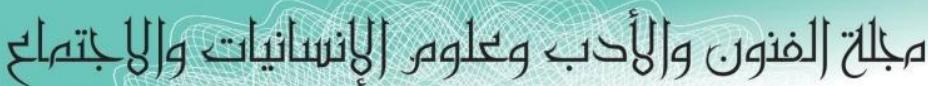

Journal of Arts, Literature, Humanities and Social Sciences

ISSN online: 2414 - 3383

ISSN print: 2616 - 3810

\section{العدد (43) ايلول - سبتمبر 2019}

ـ تقديم الحوافز المادية والمعنوية لاى مديري الدارس الذين يستخدمون الإدارة الإلكترونية في تتفيذ الأعمال

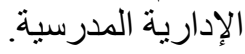
-اجراء المزيد من الدراسات في الددارس العمانية الدكومية والخاصة في مجال تطبيق الإدارة الإلكترونية

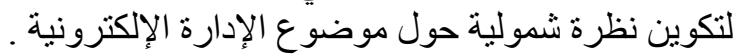
-نثر برامج توعوية لأولياء الأمور حول الأستفادة من الإدارة الإلكترونية في الدارس

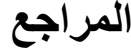

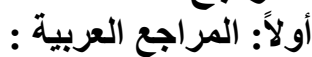

1. الأسمري ، على بن سعيد بن جالئ جازي (2009) " تطبيقات الإدارة الإلكترونية في الإدارة المدرسية ومتطلبات

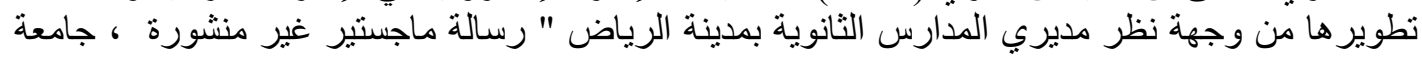

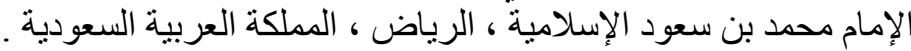

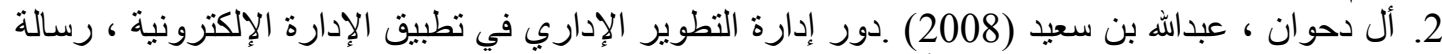

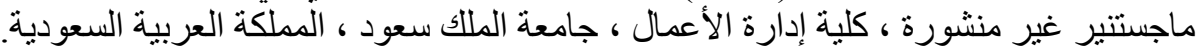

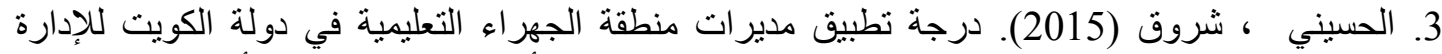

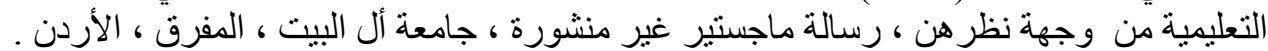

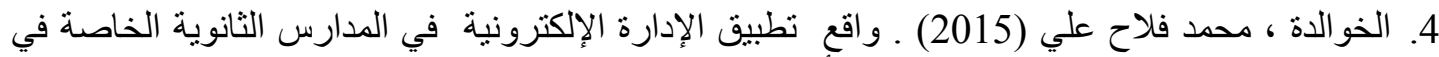

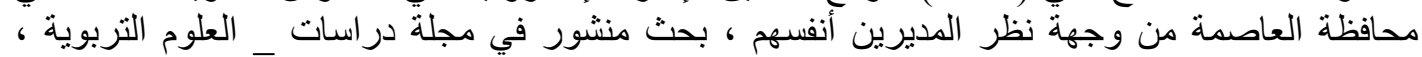

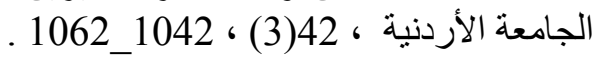

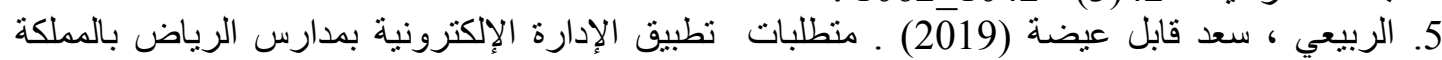

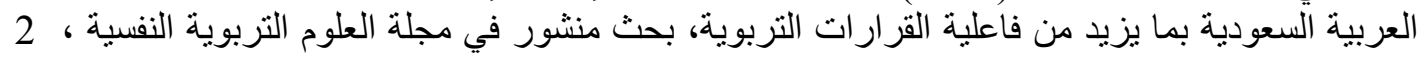
.20_1، (3) 6. الرجيبي ، رياء بنت محمد بن عامر (2006) " تطبيق خطوات مدخل الإدارة بالقيم في مدارس التعليم

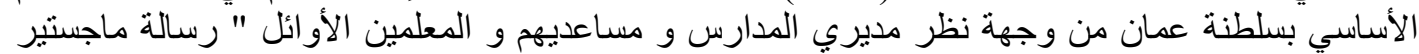

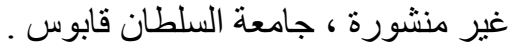

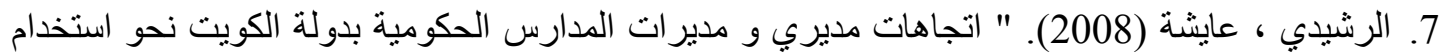

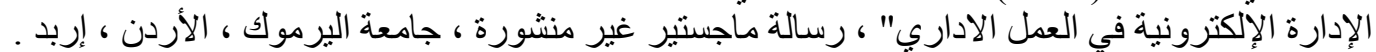

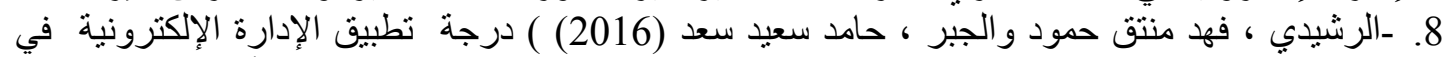
المدارس الثانوية الحكومية بدولة الكويت ، بحث منشور في مجلة كلية التربية ، جامعة أسبوط ، .586_552

9. الزعبي ، 525 ، ويسون (2014). مستوى تطبيق الإدارة الإلكترونية في المدارس الحكومية التابعة لمديرية

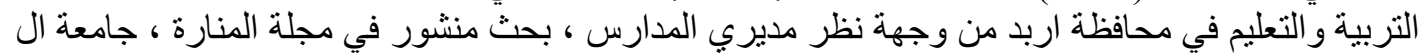

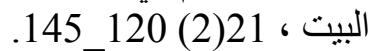

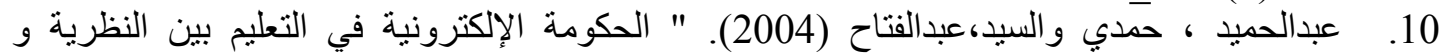

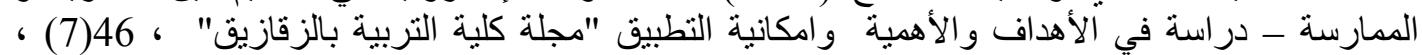
.11445 11. - عبيدو ، علي إبراهيم علي (2014). جودة البحث العلمي ، الاسكندرية : دار الوفاء لدنيا الطباعة و

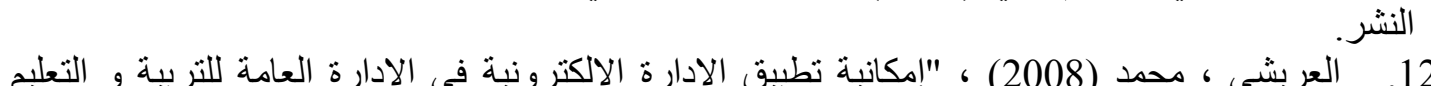

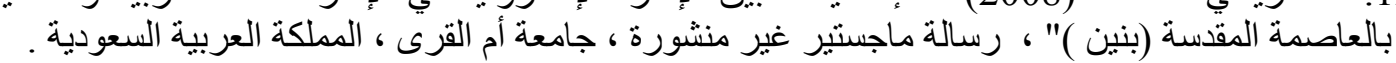
13. في الضفة الغربية ، بحث منشور في مجلة الجامع في الدراسات النفسية والعلوم التربوية ، 


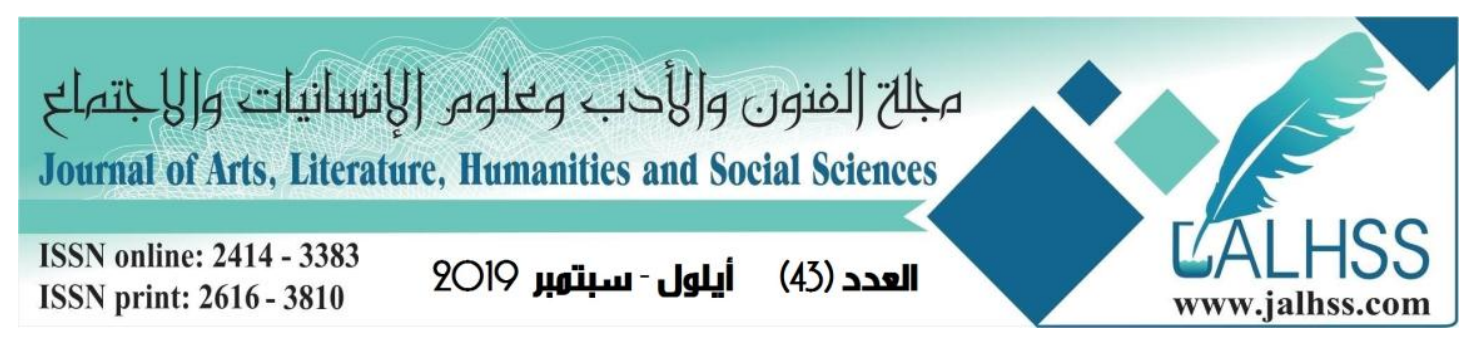

14. الماجدي ، أحمد (2006). "درجة استعداد مديري مدارس التعليم العام لتطبيق إدارة الددرسة

الإلكترونية في دولة الكويت" رسالة ماجستير غير منشورة جامعة عمان العربية ، المملكة الأردنية

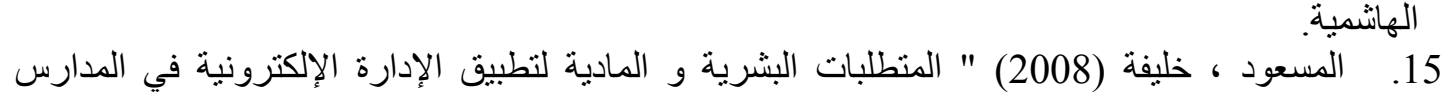

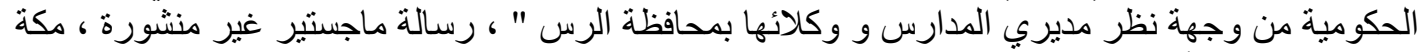

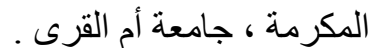

16.

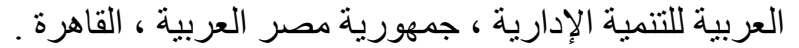

17.

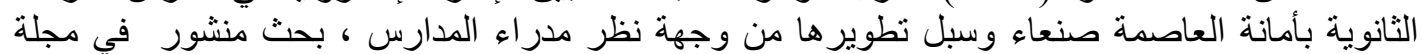

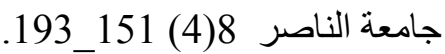
18. وزارة التربية و التعليم (2007) ـ التعليم ما بعد الأساسي ، قرار وزاري 160 ـ

19. Banoglu,k . (2011) . Educational sciences : The ory and practice , vlln 1 p208_213.6pp.

20. Crouse , D . (2004) . The principal Rules for school Technology NASSP Bulletin,Vol. 81,No.589,pp86-89.

21. Felck , c. (2010) . using computers in Croatia National univer sity Division . Journal of Research in higher Education , 2(1),111_169.

22. Li,G and Ni,X. (2011) . primary EFL Teachers , Technology use in china : patterns and perceptions , RELC Journal , April, 1,(42): 69_85.

23. Polizzi,G.(2011) . measuring school principals Support for Ict integration in Palermo Italy , Journal of media Lieracy Education , 3(2) : 113_122.

24. seresht, H (2009) . "E_Maragement : Barries and challenges in Iran". phd Dollamed Tabateebe university .

25. Serhan,D.(2007) . School principals Attitudes Towards The use of Technology : United Arab Emirates Technology work shop . The Turkish on line Journal of Education Technoligy. Volume 6 Issue2 Ariticle 5 PP $42-46$.

\section{References}

1. Asmari, Ali bin Saeed bin Jazi (2009) "Applications of electronic management in school administration and the requirements for its development from the point of view of secondary school principals in Riyadh" Unpublished Master Thesis, Imam Muhammad bin Saud Islamic University, Riyadh, Saudi Arabia.

2. Al-Dahwan, Abdullah bin Saeed (2008). The role of management development management in the application of e-management, an unpublished Magister letter, College of Business Administration, King Saud University, Saudi Arabia. 


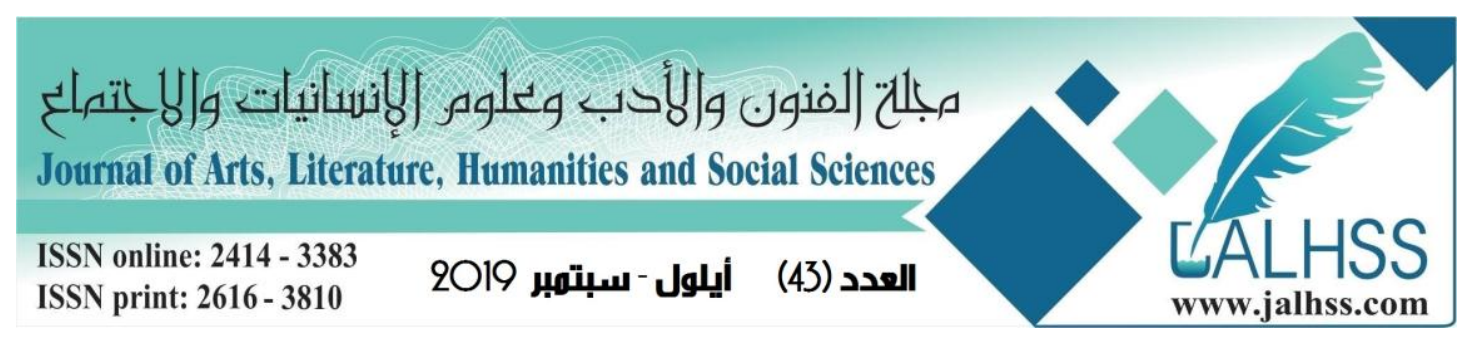

3. Al-Husseini, Shurooq (2015). The degree of application of the directors of AlJahra Educational Zone in the State of Kuwait for their educational management from their point of view, unpublished Master Thesis, Al-Bayt University, Mafraq, Jordan.

4. Alkhawaldeh, Mohammed Falah Ali (2015). The reality of the application of electronic management in private secondary schools in the Capital Governorate from the point of view of the administrators themselves, research published in the Journal of Studies _ Educational Sciences, University of Jordan, 42 (3), 1042_1062.

5. Al-Rubaie, Saad Qabl Ayida (2019). Requirements of the application of electronic management in schools in Riyadh, Saudi Arabia to increase the effectiveness of educational decisions, research published in the Journal of Educational Psychological Sciences, 2 (3), 1_20.

6. Al-Rujaibi, Raya Bint Mohammed Bin Amer (2006), "Application of Management Approach Values in Basic Education Schools in the Sultanate of Oman from the Perspectives of Principals, Assistants and Early Teachers", Unpublished Master Thesis, Sultan Qaboos University.

7. Al-Rashidi, Aisha (2008). "Attitudes of Principals and Principals of Public Schools in the State of Kuwait Towards the Use of E-Management in Administrative Work", Unpublished Master Thesis, Yarmouk University, Jordan, Irbid.

8. Al-Rashidi, Fahad Mintaq Hamoud and Al-Jabr, Hamed Saeed Saad (2016), the degree of application of electronic management in public secondary schools in the State of Kuwait, research published in the Journal of the Faculty of Education, Assiut University, 32 (1), 552_586.

9. Zoubi, Mason (2014). The level of application of e-management in public schools of the Directorate of Education in Irbid Governorate from the point of view of school principals, research published in Al-Manara Magazine, Al-Bayt University, 21 (2) $120 \_145$.

10. Abdul Hamid, Hamdi and Sayed, Abdel Fattah (2004). "E-government in education between theory and practice - a study in the objectives, importance and applicability" Journal of the Faculty of Education Zagazig, "46 (7), 45_114.

11. Abido, Ali Ibrahim Ali (2014). The quality of scientific research, Alexandria: Dar Al Wafaa for printing and publishing.

12. Al-Arishi, Mohammed (2008), "The possibility of applying e-management in the General Administration of Education in the Holy Capital (Boys)", unpublished Master Thesis, Umm Al-Qura University, Saudi Arabia.

13. Otair, Rabih Shafiq (2017). The degree of availability of the requirements of the application of electronic management in private schools in the West Bank, a research published in the Journal of the Whole in Psychological Studies and Educational Sciences, 2 (6) 12_37.

14. Al-Majidi, Ahmad (2006). "The degree of readiness of the principals of general education schools to apply the management of e-school in the State of Kuwait" Unpublished Master Thesis Amman Arab University, Hashemite Kingdom of Jordan. 


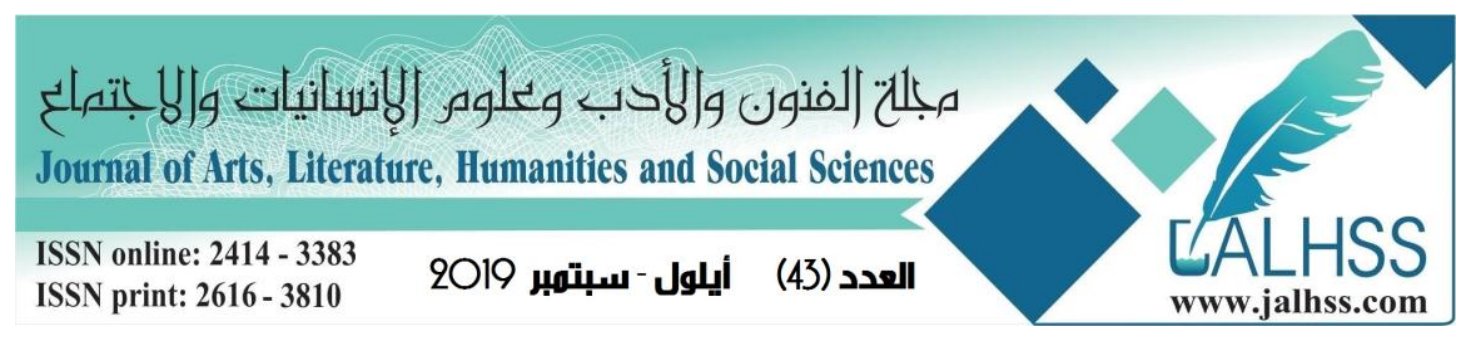

15. Al-Masoud, Khalifa (2008), "Human and Physical Requirements for the Application of E-Management in Public Schools from the Perspective of School Principals and Agents in Al-Rass Governorate", Unpublished Master Thesis, Mecca, Umm Al-Qura University

16. Almafraji, Adel (2007). E-Management: Intellectual Foundations and Requirements for Establishing a Process, Arab Administrative Development Organization, Arab Republic of Egypt, Cairo.

17. Al-Nu'man, Mohammad Hammoud (2016). The degree of availability of the requirements of the application of electronic management in secondary schools in the capital Sana'a and ways to develop them from the point of view of school principals, research published in the Journal of the University of Nasser 8 (4) 151_193.

18. Ministry of Education (2007). Post-Basic Education, Ministerial Decree 160. 